$\frac{12}{4-4948} \delta 010$

UCRL-ID-115605

\title{
Development of Flammable Liquid Storage Wooden Cabinets for Chemical Laboratories
}

\author{
K.J. Staggs
}

H.K. Hasegawa

S.M. Doughty

J.G. Barr

November 1993

This is an informal report intended primarily for internal or limited external distribution. The opinions and conclusions stated are those of the author and may or may not be those of the Laboratory.

Work performed under the auspices of the U.S. Department of Energy by the Lawrence Livermore National Laboratory under Contract W-7405-Eng-48. 


\section{DISCLAIMER}

This document was prepared as an acccount of work sponsored by an agency of the United States Government. Neither the United States Government nor the University of California nor any of their employees, makes any warranty, express or implied, or assumes any legal liability or responsibility for the accuracy, completeness, or usefulness of any information, apparatus, product, or process disclosed, or represents that its use would not infringe privately own rights. Reference herein to any specifie commercial products, process, or service by trade name, trademark, manufacturer, or otherwise, does not necessarily constitute or imply its endorsement, recommendation, or favoring by the United States Government or the University of California. The views and opinions of authors expressed herein do not necessarily state or reflect those of the United States Government or the University of California, and shall not be used for advertising or product endorsement purposes.

This report has been reproduced directly from the best available copy.

Available to DOE and DOE contractors from the Office of Scientific and Technical Information

P.O. Box 62, Oak Ridge, IN 37831

Prices available from (615) 576-8401, FTS 626-8401

Available to the public from the National Technical Information Service

U.S. Department of Commerce 5285 Port Royal Rd., Springfield, VA 22161 


\title{
Development of Flammable Liquid Storage Wooden Cabinets for Chemical Laboratories
}

\author{
Prepared for \\ Lawrence Livermore National Laboratory \\ Nuclear Chemistry Division \\ Building 151
}

\author{
by \\ K.J. Staggs \\ H.K. Hasegawa \\ S.M. Doughty \\ J.G. Barr
}

November, 1993

Fire Research Discipline

Special Projects Division

Hazards Control Department

Lawrence Livermore National Laboratory

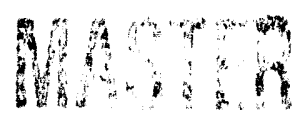




\title{
Development of \\ Flammable Liquid Storage Wooden Cabinets for Chemical Laboratories
}

\begin{abstract}
A fire hardened wooden cabinet was developed for the storage of flammable liquids for LLNL Bldg. 151 nuclear chemistry laboratories. The new cabinet requirements were to fit into existing cabinet spaces, match existing cabinets in appearance, and meet the National Fire Protection Association Flammable and Combustible Liquids Code. A standard test apparatus was developed to produce the required fire exposure necessary to evaluate existing cabinets and new designs. The final design was a cabinet insert that could be prefabricated and installed into the appropriate storage area of the existing cabinets.
\end{abstract}

\section{Project Description}

The primary objective of this project was to develop a method of fire hardening existing wooden laboratory cabinets in Building 151 so that they would comply with the requirements of NFPA 30 for flammable liquid storage. The chemistry labs generally contain 2 to 25 liters of flammable liquids stored in plastic bottles ( 0.5 to 4 liters) and in metal cans ( 1 gallon). Most of these liquids had previously been stored in cabinet spaces beneath built in wooden work benches. Because the quantities of flammable liquids sometimes exceed those for daily use, the excess must be stored in cabinets that meet the requirements of National Fire Protection Agency (NFPA) Flammable and Combustible Liquids Code (NFPA 30) [1]. Qualifying cabinets must withstand a 10 minute fire exposure using the standard time-temperature curve as prescribed in ASTM E-152-81a [2] without exceeding an internal air temperature of $163^{\circ} \mathrm{C}\left(325^{\circ} \mathrm{F}\right)$.

A typical solution to this requirement has been to install certified, metal flammable liquid cabinets. However, this tactic may not always be practical, may not be esthetically pleasing, and maybe costly. The existing wooden cabinets are built-in units. They are integral with the counter tops and include typical analytical lab fixtures. Furthermore, independent testing by others has shown that a number of certified metal cabinet brands do not provide the protection intended by the NFPA standard. Therefore, this project was initiated to develop fire hardened wood cabinets, preserve the chemistry laboratory benches outward appearance and comply with the NFPA code. 


\section{Fire Test Apparatus}

A medium scale fire test apparatus which could reproduce the fire exposure specified in the NFPA 30 standard was constructed and verified.

The basic test plan was to construct a medium scale furnace to provide the ASTM E-119 fire exposure for cabinet evaluation. This furnace is shown in figure 1 and photos 1 through 4 . The furnace was designed specifically to accommodate cabinet sections from Bldg. 151. A total of twelve 12"x 6" gas fed radiant panels were used as the heat source. Four thermocouple probes were inserted past these burners approximately 18 " into the furnace. The average temperature from these probes was used to determine furnace temperature during the tests. The heat output of this furnace provides a standard time temperature curve of $538^{\circ} \mathrm{C}\left(1000^{\circ} \mathrm{F}\right)$ at 5 minutes and $704^{\circ} \mathrm{C}\left(1300^{\circ} \mathrm{F}\right)$ at 10 minutes, measured $6^{\prime \prime}$ from the face of the test specimen.

The furnace is controlled manually by a remote pressure regulating valve. During each test the wood facing of the cabinet ignited as shown in photo 5 . When this occurred the furnace output was reduced to compensate for this additional energy. Later on in the test the furnace output was slowly increased to maintain the required temperature. Typically, by the end of a test the furnace approached its maximum output of 240,000 British Thermal Units per hour.

\section{Summary of Testing and Development}

The initial test $(\mathrm{CAB} 1)$ in the series was conducted to assess the fire resistance of an exemplar cabinet section. Photos 6 and 7 shown the placement of the cabinet in the furnace. A thermocouple was installed in the center of the cabinet one inch down from the top. The post test inspection revealed that the fire eroded the edge of the cabinet door and that the door warped slightly outward at the top. This permitted the entrance of hot fire gases, which instantaneously exceeded the internal temperature limit. Photo 8 shows the heat pattern from hot gases penetrating along the edge of the door at the upper hinge side. This failure is reported in the interior temperature plot of figure 2 by a sudden rise in temperature, occurring at 210 seconds into the test, exceeding the temperature limit $\left(325^{\circ} \mathrm{F}\right.$ or $\left.163^{\circ} \mathrm{C}\right)$ set by the NFPA 30 standard.

After studying the physical damage to the cabinet, as well as the findings of the Los Angeles Fire Department (LAFD Standard No. 40, 1-1-60) for cabinet design, we designed a fire hardened prototype. The general concept for the prototype was to prefabricate a complete box which met the criteria. These boxes would then be inserted into the existing wooden chemistry benches. The cabinet was basically a 
plywood box with a cabinet door. Prefabrication would not only be economical, but more importantly, it would facilitate good quality assurance on the construction of each cabinet.

In order to meet the test requirements, the cabinet design had to prevent flames and/or hot fire gases from breaching or leaking into the cabinet storage area for at least 10 minutes. A series of three tests was conducted to develop the final design which met the criteria of NFPA 30. The evolution of the fire hardened cabinet primarily involved refining details of the insert door. To be cost effective and provide a visual means of detecting failures we had only the front $25 \%$ of the cabinet built (see in photo 9) for tests CAE2. 3 , and 4. The critical details to consider involved the following details of the insert door:

- The fire endurance of the door panel.

- The seal around the door edges.

- The strength of the hinges.

- The strength of the door latches.

Each of the three prototype tests were conducted to determine and solve the modes of failure, endurance time, solutions, and final design. Once these problems were systematically solved, two full scale cabinets were constructed and tested to verify the partial mock ups of these cabinets.

In the second test ( $\mathrm{CAB} 2$ ) a cabinet section was fabricated and instrumented as shown in figures 3 and 4. Thermocouples were placed on the surface of the door face and back. Four additional thermocouples were located approximately $1 / 2$ inch from each inside corner of the door. The cabinet was placed in the furnace as shown in figure 5 and exposed to the temperature levels based on the time temperature curve. The graph in figure 6 shows that at approximately 150 seconds into the test a significant temperature rise occurred along the top of the door, indicating the door seal had failed. A post test inspection revealed that the door warped outward at the top causing a slight opening along the seal. The penetrating hot gases and flames quickly eroded the edge of the door causing the screws that mount the hinges to the door to come out. It was also determined that an additional contributing factor to the door failure was the poor fit of the door latches. The bolt latches used to hold the door shut did not apply tension on the door, but instead, maintained a slight gap around the door. This gap permitted hot gases to penetrate the door seal and degrade the edge.

To address these failures a third test (CAB3) was conducted. For this test a cabinet mock up was constructed (shown in figure 7) with a thicker door, stronger hinges, and roller latches. The door was made thicker to prevent it from warping and pulling the latches open. The selected hinges for this unit (shown in photo 10) were industrial grade with the screw mounts further inboard from the door edge. This insured 
that the screws were out of the area where degradation had occurred in the cabinet door tested in the second test. The roller latches, shown in photos 11 and 12, were installed to apply tension on the door and keep it tightly closed.

This unit was instrumented with 4 thermocouples, located approximately $1 / 2$ inch from the inside corners near the door (see figure 4).

The graph, shown in figure 8, of temperature plots from this test, indicates that hot gases were penetrating the door seal at each comer early in the test. These plots also show that the door and/or door seal completely failed at 500 seconds into the test. Post test inspection of this cabinet unit revealed that hot gases penetrated the door seal and melted the plastic rollers in the latches, thereby releasing the door. Further inspection indicated that the gap between the door and the cabinet (door seal) was too wide. This was primarily because the larger hinges were not recessed enough. The temperature plots confirm this by showing that the internal temperature increase was on the hinge side of the door.

Based upon the findings from test 3 we decided to use a slightly different hinge design, change the tolerances for the hinge installation, and use ball latches that had all metal components. Figure 9 shows the details of these changes. The new hinges, shown in photo 13, allowed the door to close tighter, and placed the mounting screws holes further inboard on the door. The cutout for these hinges was sized to provide a 1/32 inch or less door seal gap. The all metal ball latches, shown in photo 14 , werc installed and adjusted to keep constant tension on the door while holding it closed. This modified cabinet mockup was evaluated in test 4 (CAB4).

For this test the cabinet mockup was instrumented with 4 thermocouples. A thermocouple was place on the face of the door to determine whether the exposure to the door was consistent with the pervious tests. A thermocouple was placed on the door back to determine the heat transfer through the door. Two additional thermocouples were located behind the door in the upper corners above the latches and hinges.

The temperature plots, shown in figure 10, show that hot gases penetrated through or past the door hinges. However, the door remained tightly closed and intact over the required exposure period. Additional analysis of this data showed that the door received the same fire exposure as in previous tests. The hot gases penetrating past the hinges had little if any effect on the latch or operation of the door seal. The final analysis of this test determined that the quantity of hot gases, penetrating past the hinges, would not elevate the overall internal temperature in a cabinet of this size to above the allowable limit of $163^{\circ} \mathrm{C}$ $\left(325^{\circ} \mathrm{F}\right)$.

To confirm our findings we fabricated two complete full scale cabinet inserts (shown in figure 11), installed them into an actual laboratory cabinet section, and then evaluated them in the test furnace. Photos 
15 to 21 show the detail of the cabinet insert construction. Photo 22 shows the placement of the laboratory cabinet, with the cabinet insert, in the furnace.

In the first full scale test (FULLCAB1) we inserted one thermocouple into the center top of the cabinet insert 1" down from the top. The temperature plot, shown in figure 12, shows that the internal temperature of this cabinet did not exceed $75^{\circ} \mathrm{C}$ during the test. Although the face of the cabinet section was flaming during most of this test and was badly charred, the door remained closed and intact, with the internal temperature staying well below the limits specified in the standard.

In the second full scale test (FULLCAB 2) we added two additional thermocouples. One was placed in the mid area of the small drawer above the cabinet insert and the other was placed in the top large drawer along side of the cabinet insert. These measurements were taken to determine what the thermal exposure was to the top and sides of the cabinet insert. A plot of these temperature measurements is shown in figure 13. As in the previous test the face of the cabinet was flaming over most of the test period. The door remained closed and intact with the internal temperature well below the limits specified in the standard. The temperature of the drawers also stayed below the limits of the standard, but it was significantly higher then the temperature inside the cabinet insert.

\section{Cabinet Design Criteria}

An overall detailed drawing of the design cabinet insert is shown in appendix 1 . The call outs in this drawing specify that the door be made of 1-1/4" thick high grade birch veneer plywood with no voids. This is to insure that when the fire penetrates the first layer of the door the subsequent layers continue to impede the fire's progress. Photo 23 shows an example of the deep charring that occurred during these tests. One or more voids in the plywood layers used to construct the door could allow the fire to penetrate the door. The specified thickness of the door is necessary to minimize heat transfer through the door, and to insure that enough unburned wood is left to maintain the door integrity, and to minimize warpage. In the original cabinet test ( $C A B 1)$ the door warped which contributed to its failure. The trim around the door is attached using a spline method as called out in the drawing. This was done to insure that the trim stayed in place to protect the edge of the door. Loss of this trim piece early on in the fire would allow excessive degradation of the door edge which could result in the failure of the door seal.

As stated previously in this report, the specified hinges were selected because their length allowed the screws to be placed further inboard on the door. This insured that the hinge screws would not be in the area of the door where degradation might occur in a fire. These hinges were also selected because they 
would mount securely to cabinet insert side walls, close tighter than other similar hinge designs, and provide a long service life.

The specified ball latches were selected because they could be set to provide constant tension on the door when it was closed. Since they are all metal, hot gases seeping through the door seal would not cause them to release. A solid piece of wood, spanning the back of the door, was used to mount these latches securely to the door. This wood also strengthens the door along the latching side, which minimizes warping due to the thermal stress from a fire. The elongate strike plate for the latches is necessary to permit some means of adjustment, insure a durable and firm location for the latch ball to fit into, and to prevent the ball from gouging the side wall.

A clear finish was specified for the door and trim to match the existing cabinet section. The handle from the original cabinet was installed on the door of the cabinet insert so that it would also match the existing cabinet handles.

The box was designed to provide a proper mate for the door seal. It also allows the entire cabinet insert to be prefabricated to the proper specifications in a controlled shop area. The size of the box was designed to be slightly smaller than the existing cabinet spaces located in LLNL bldg. 151 Nuclear Chemistry Laboratories to simplify field installation. Shims were used to center the cabinet insert in the existing cabinet space. Bugle or flat head wood screws of sufficient length were used to hold the cabinet insert in place. Trim pieces, shown in Photo 20, were installed around the edges of the cabinets to cover the gap between the cabinet insert and the existing cabinet.

\section{Requirements}

In order for these fire hardened wood cabinets to comply with the NFPA code they must be constructed as describe in the drawing (No. LEA 93-1402-01-F-0), which is included in this report in Appendix 1. Furthermore, warning signs and secondary containment must be provide. If used for the storage of flammable liquid this cabinet must be labeled "FLAMMABLE-KEEP FIRE AWAY" as required by the NFPA 30 section 4-2.2 In addition, a secondary containment pan that can contain a 2 inch level of liquid must be installed in the bottom of these cabinets as required by the NFPA 30 section 4-3.2.2. Based upon the dimensions of this containment pan the quantity of stored flammable liquid must not exceed 3 gallons unless additional secondary containment is provided.

There can be no modification, substitution or penetration made in or to this cabinet. One exception is that the overall size or dimensions of this cabinet may be reduced to fit into other similar type laboratory 
cabinet spaces. However, the wood type and thickness must meet specification as well as the hinges and door latches. Cabinets made to larger dimensions must be tested as listed in this report.

These cabinet inserts were designed and intended to be located within another cabinet. This designed installation provides some degree of protection for the cabinet insert box section. Since these cabinets were designed and tested with this intent, they must be installed within this type of cabinet space. If a stand alone unit is desired a surrounding cabinet structure must be constructed that provides the same degree of protection as these existing laboratory cabinets.

These cabinet insert must be inspected annually to insure their integrity. This inspection should include the following:

- an inspection of the door panel for delamination or penetrations.

- inspection of the hinges for wear and to insure that the hinge screws are tight.

- inspection of the latches for proper fit and tension, and that the strike plate is properly attached.

- inspection of the door seal for wear, and to insure that the door seal gap is set to $1 / 32$ " or less.

\section{Conclusions and Recommendations}

When properly constructed, installed, and maintained, these cabinet inserts will provide a proper storage area for flammable liquids. Tests have shown that these cabinet inserts will provide the necessary protection against fire as required by the NFPA 30 standard. However, any modifications or installation changes could effect the degree of protection these cabinet inserts were designed to provide. Modification or changes must be evaluated and tested to determine their effect on the fire performance of these cabinet inserts.

A Quality Assurance program should be implemented to insure that these cabinets meet the required specifications, and that they are properly installed and maintained. Occasionally, completed cabinets should be randomly selected and subjected to a repeat fire test to confirm that production has not introduced an unexpected degradation in performance. 


\section{References}

1. National Fire Protection Association, Volume 2, Flammable and Combustible Liquids Code, NFPA 30, section 4-3, Design, Construction, and Capacity of Storage Cabinets, (1993).

2 American Society for Testing and Materials, Annual Book of ASTM Standards, Volume 04.07, Designation: E152-81a, Standard Method of Fire Test Of Door Assemblies. (1990). 



\section{Furnace used for E119 Time Temperature Curve Exposure}

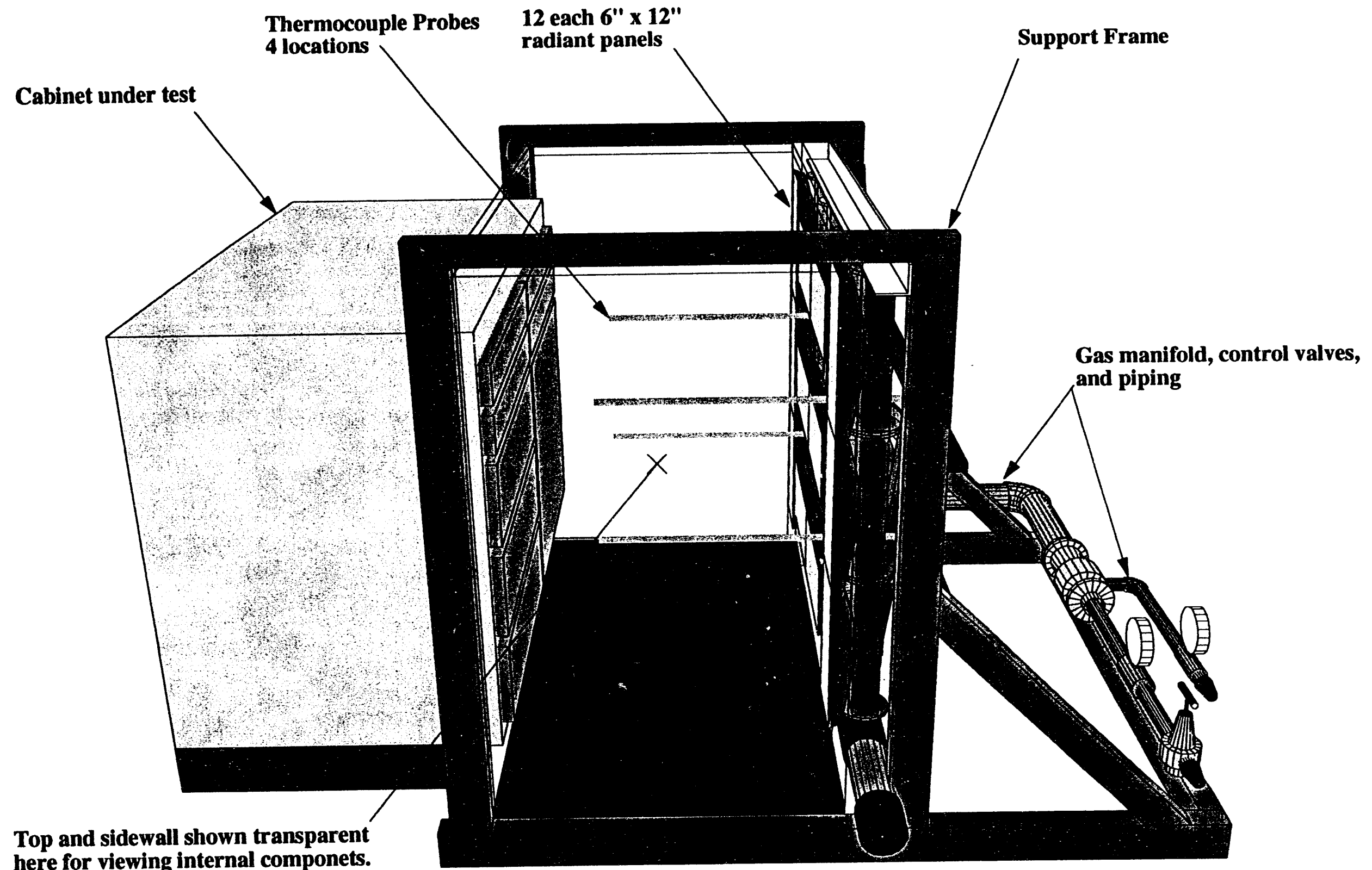

here for viewing internal componets. Actual sidewall are made of stainless steel sheeting and fiberfrax insulation. 


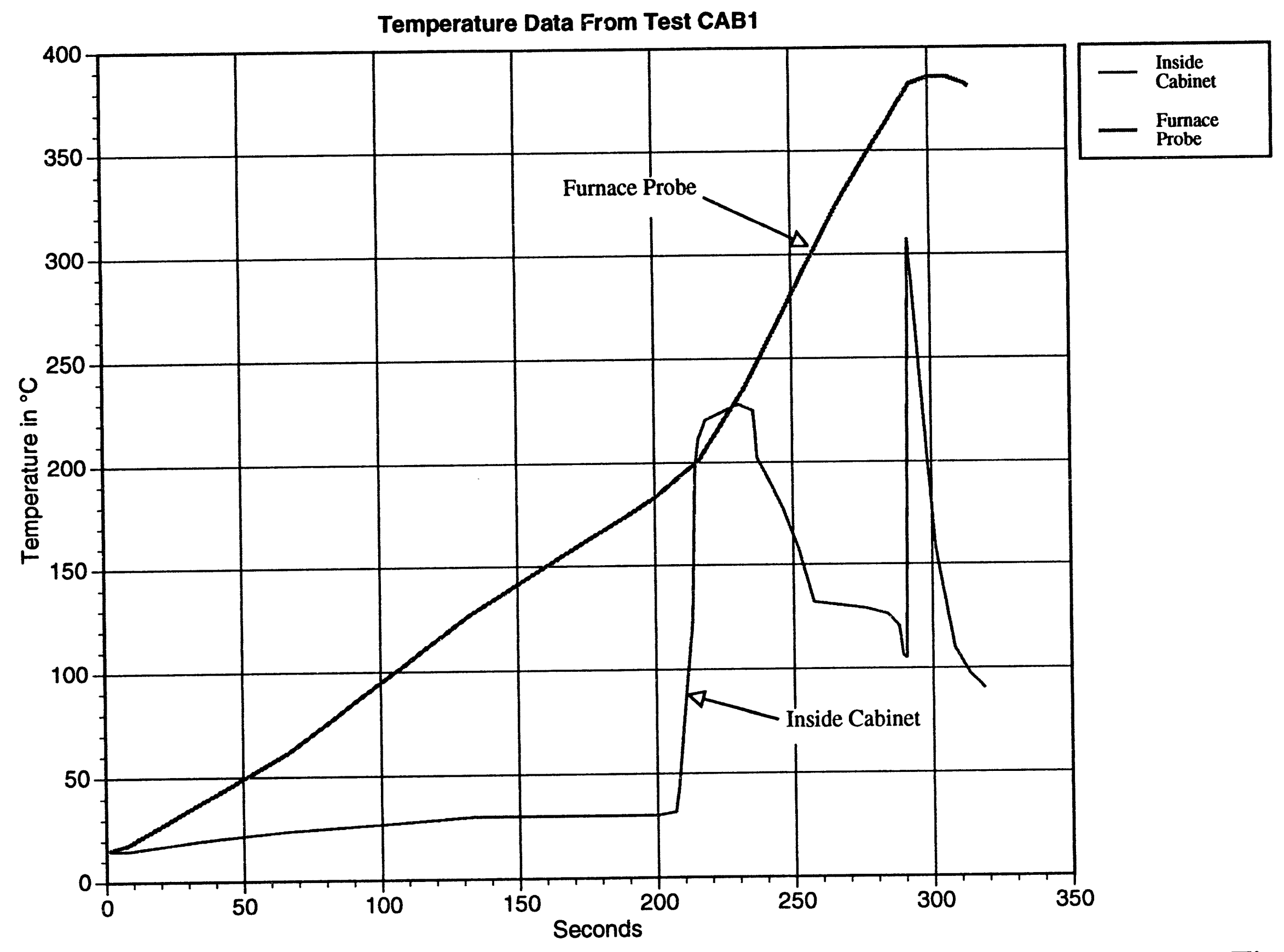

Figure 2 

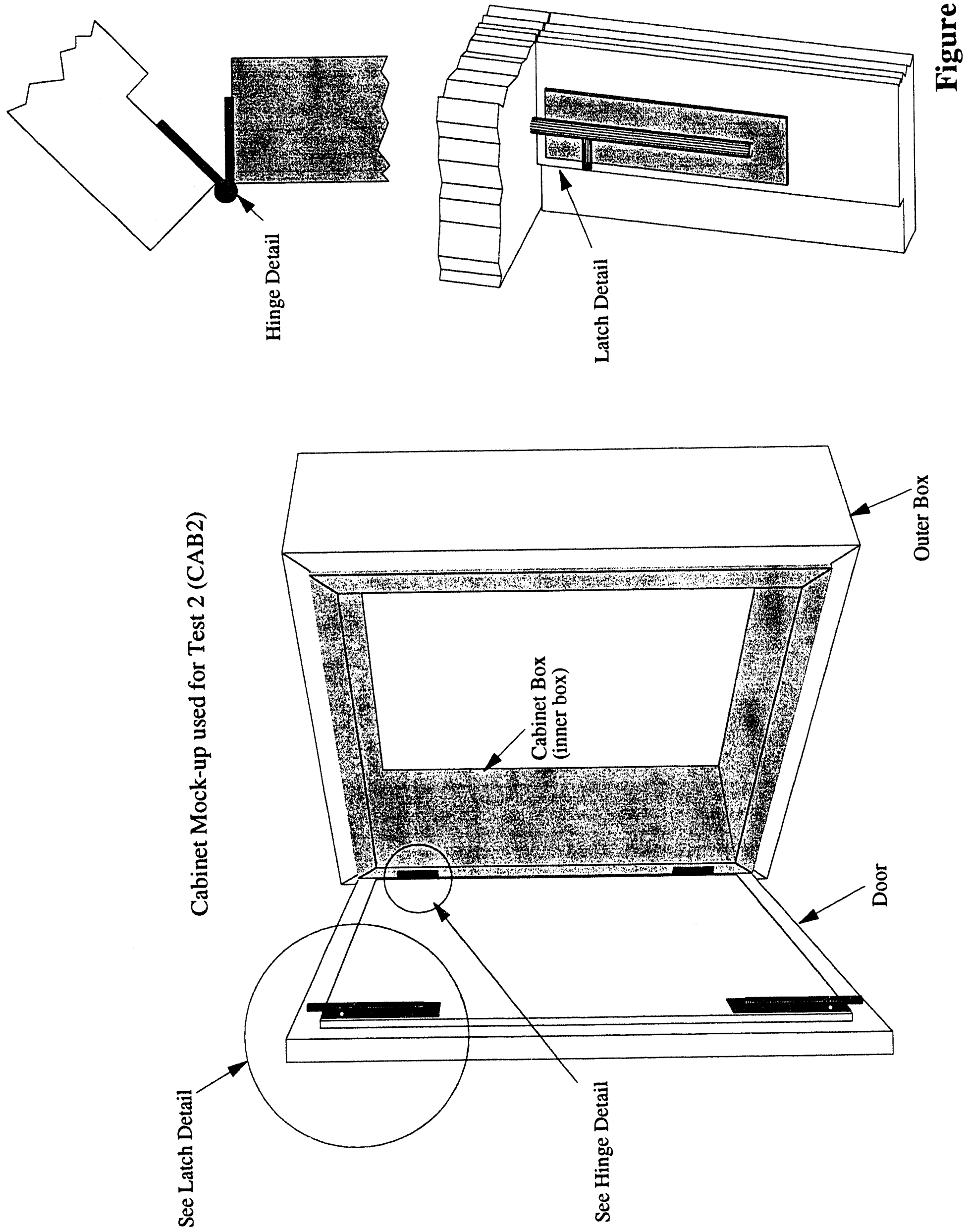


\section{Thermocouple Locations for Tests 2-4}

All thermocouples were monitored for test 2 . See legends of tests 3 and 4 temperature plots for location of themocouples monitored in these tests.

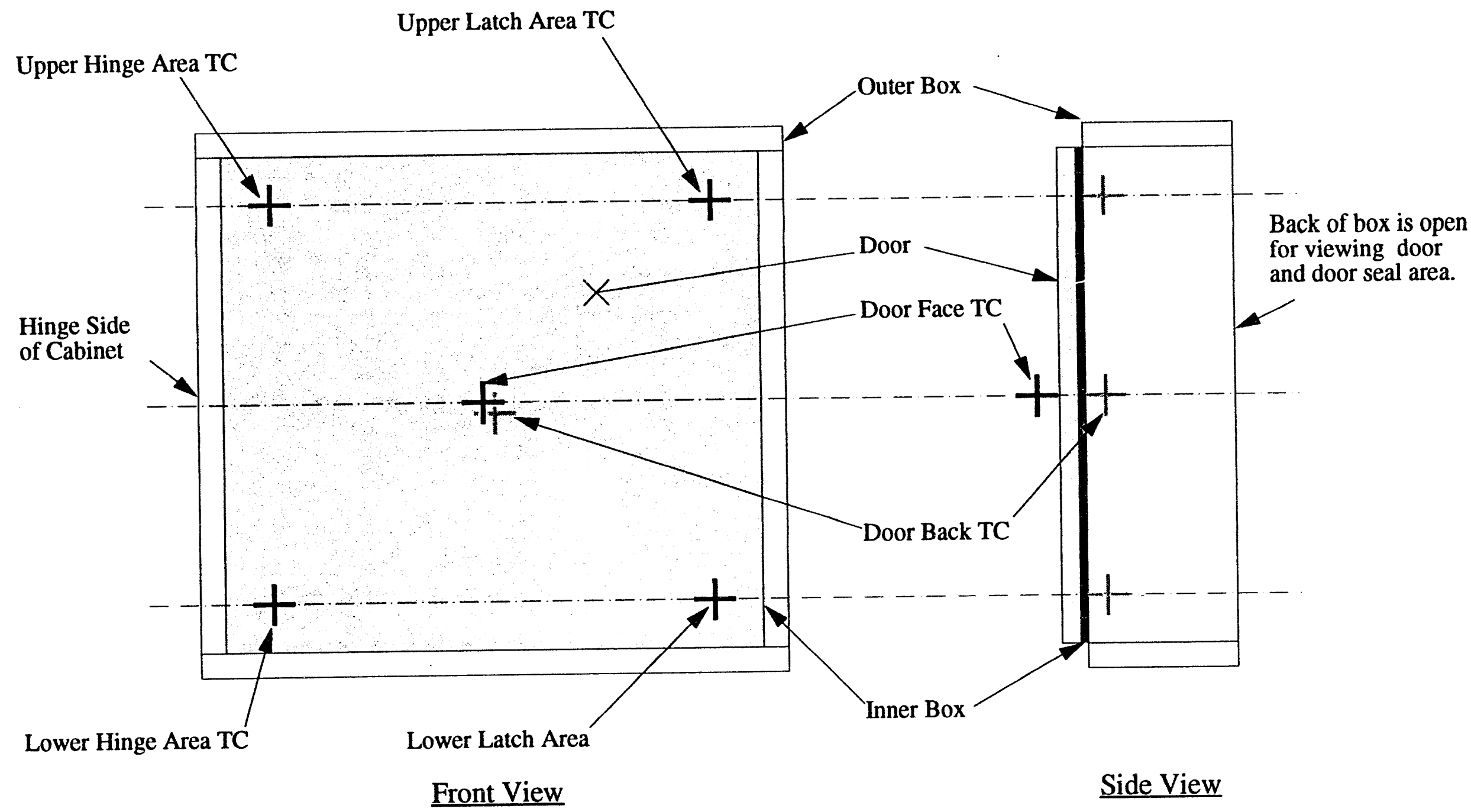




\section{Placement of Cabinet Mock up in the Furnace used for E119 Time Temperature Curve Exposure}

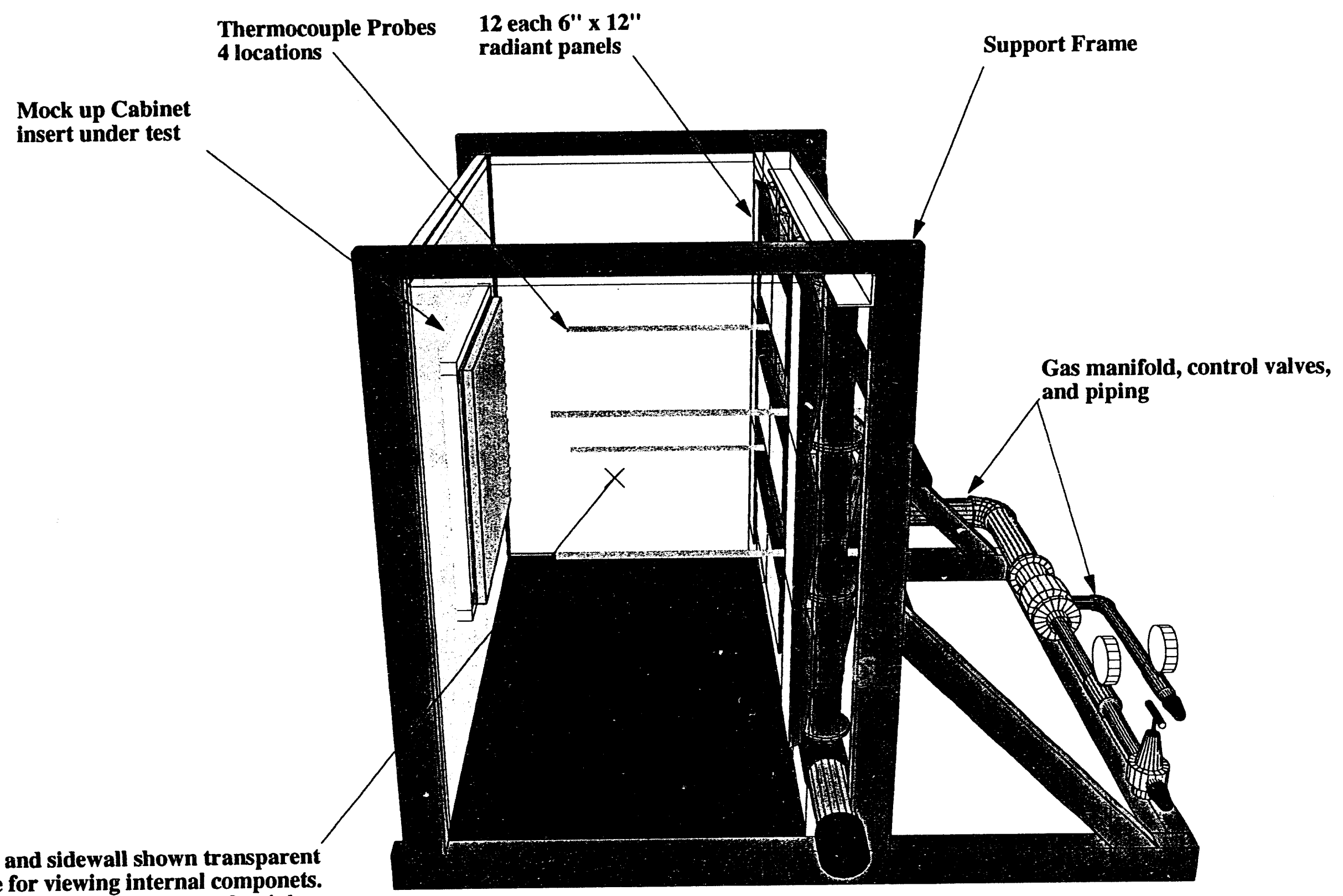


Temperature Data From Test CAB2

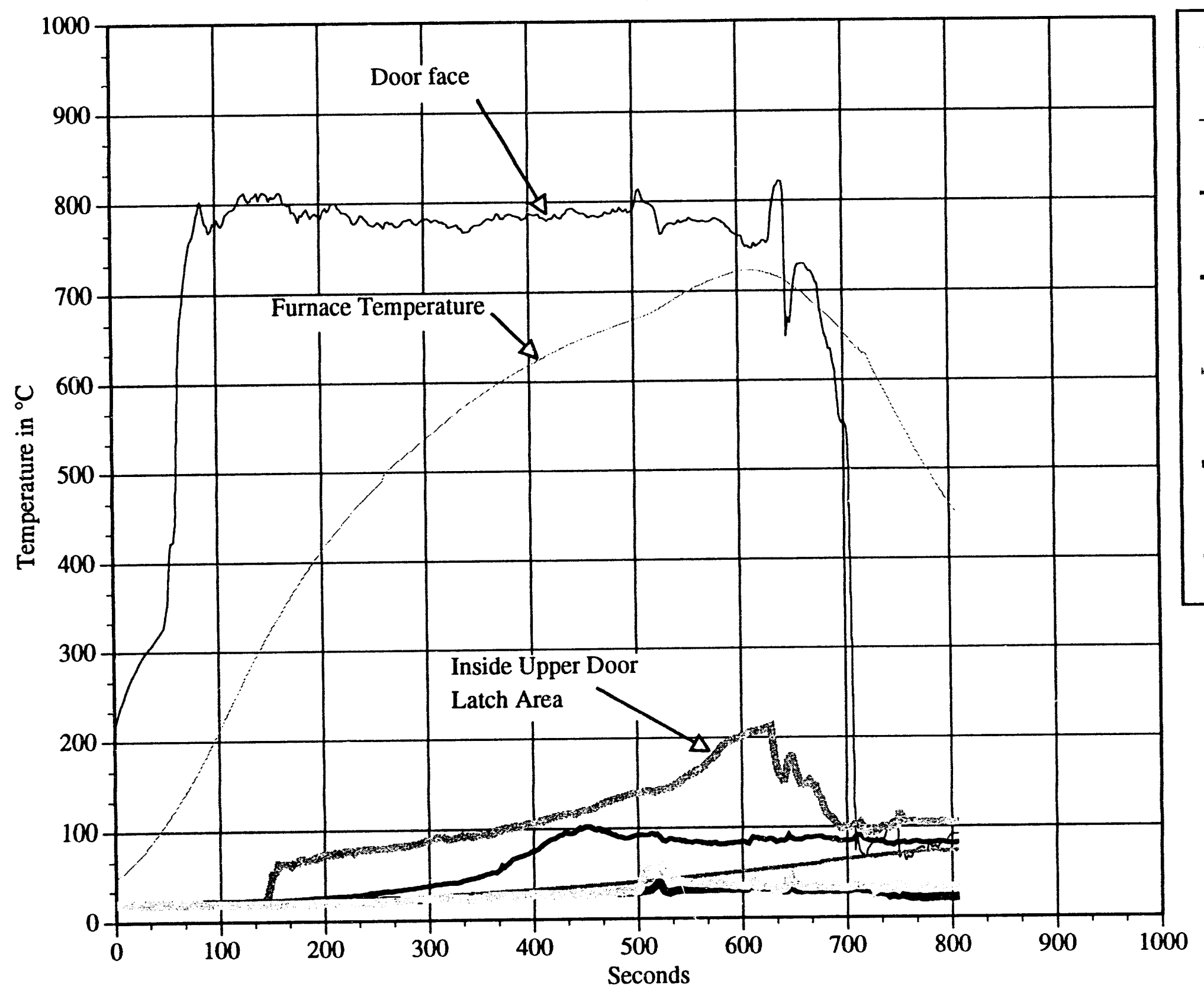

Furnace

Temperature

Center Of Door Face

Center of Door Back

Inside Upper

Door Hinge

Area

Inside Upper Door Latch

Area

Inside Lower

Door Hinge

Area

Inside Lower

Door Latch

Area 


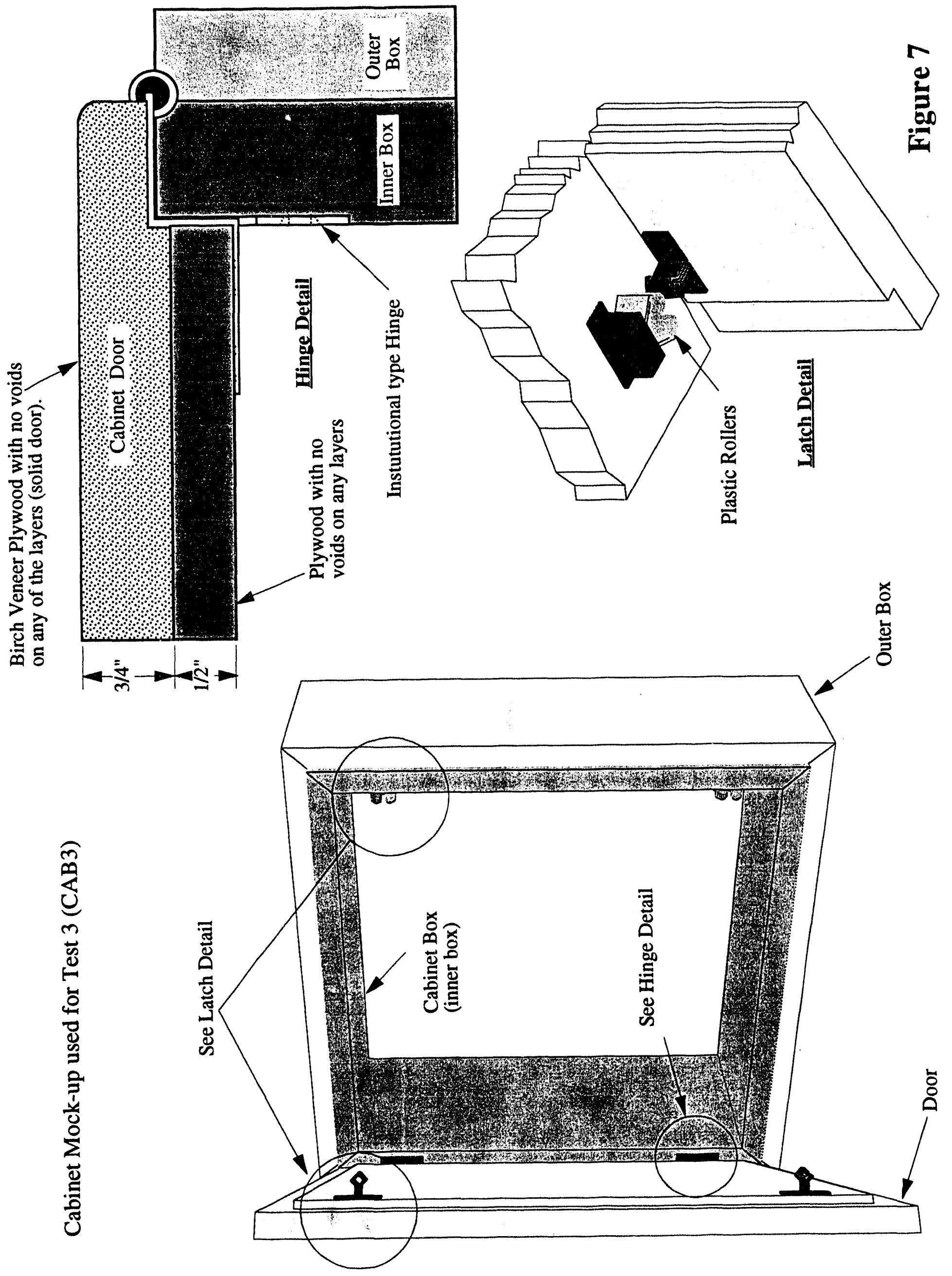


Temperature Data From Test CAB3

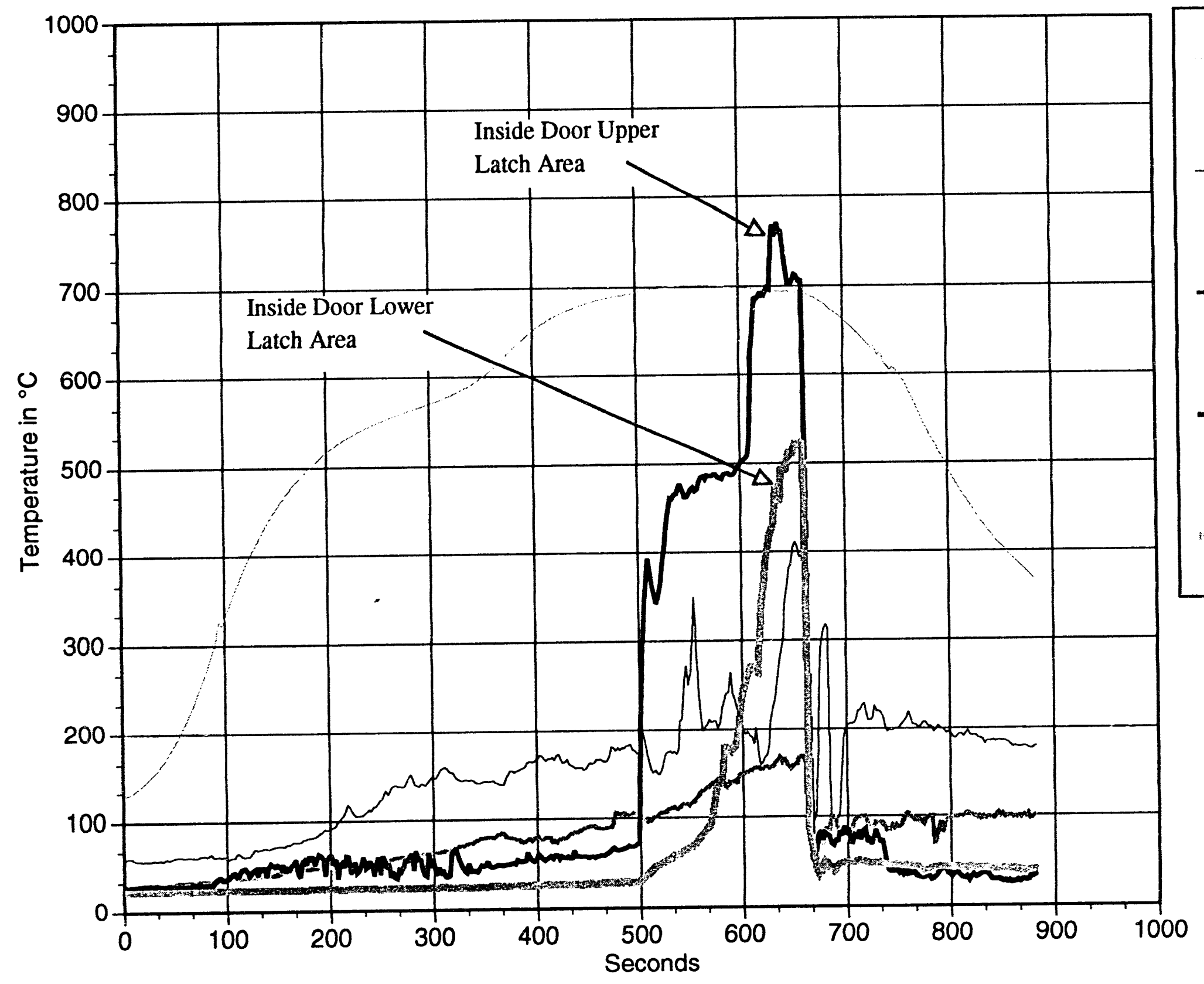

Furnace

Temperature

Inside Door

Upper Hinge

Area

Inside Door

Lower Hinge

Area

Inside Door

Upper Latch

Area

Inside Door

Lower Latch

Area

Figure 8 


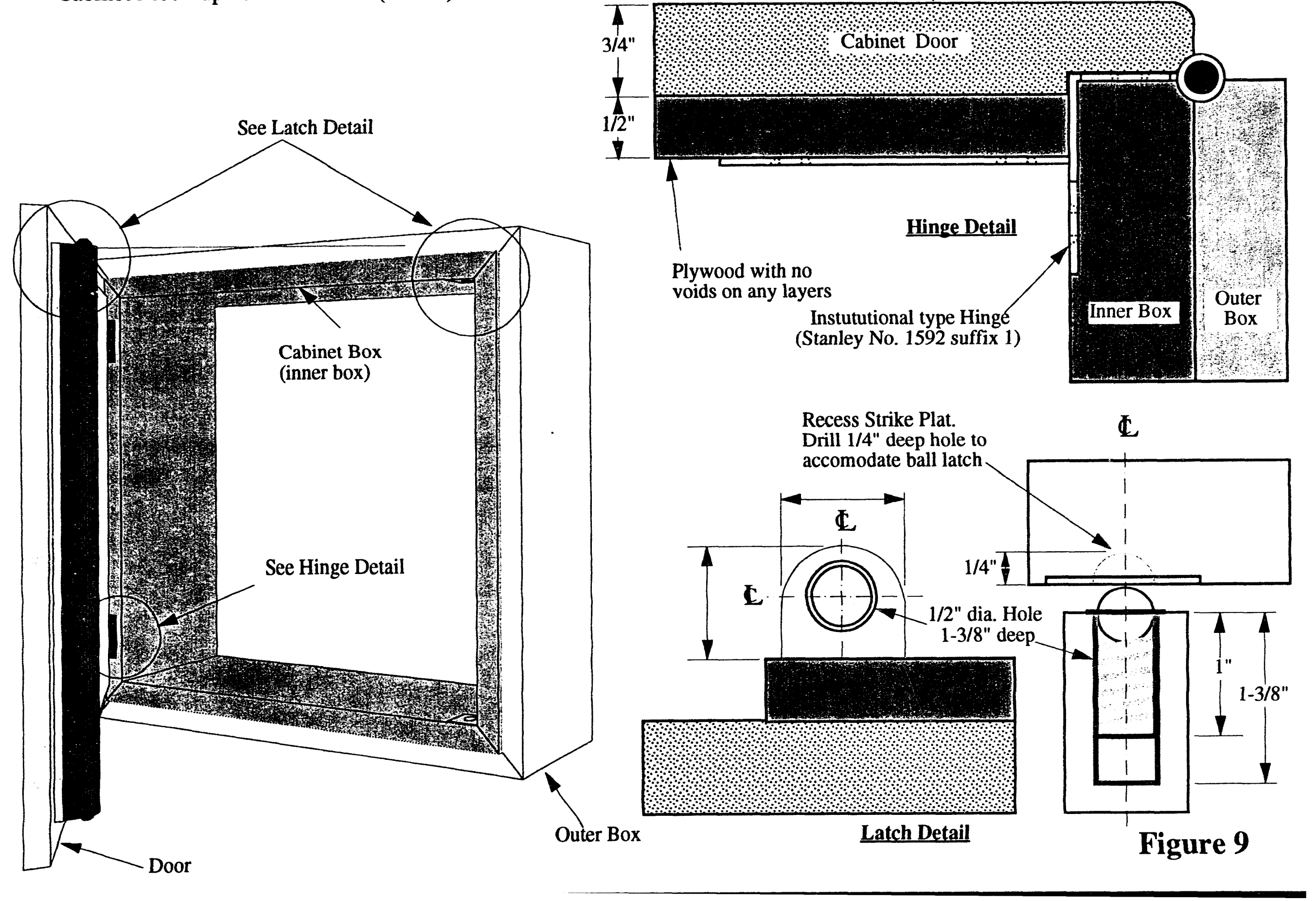

Birch Veneer Plywood with no voids on any of the layers (solid door). 
Temperature Data From Test CAB4

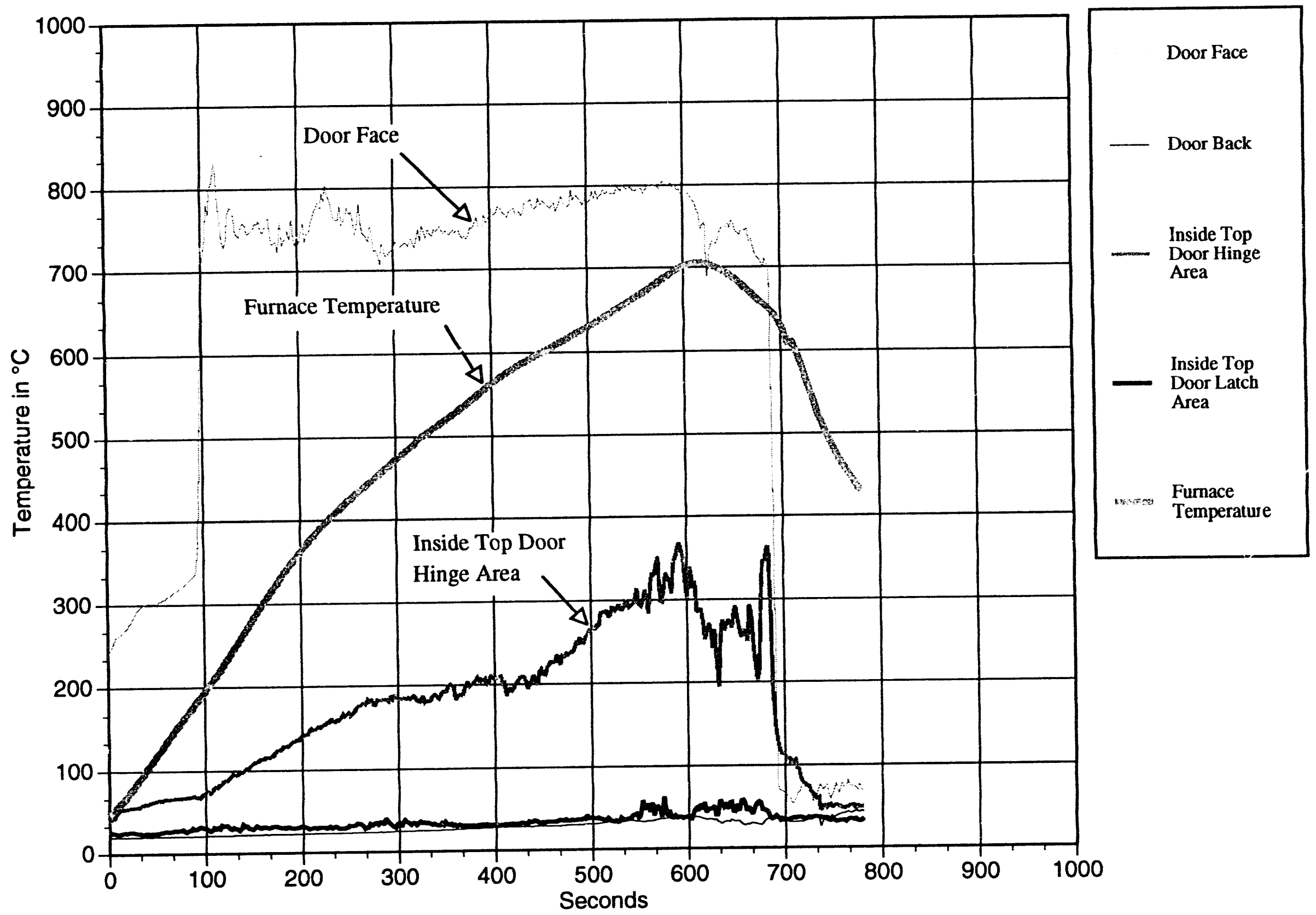

Figure 10 
Final Fire Hardened Cabinet Design Tested in Test 5 and 6 (FULLCAB 1 and 2)

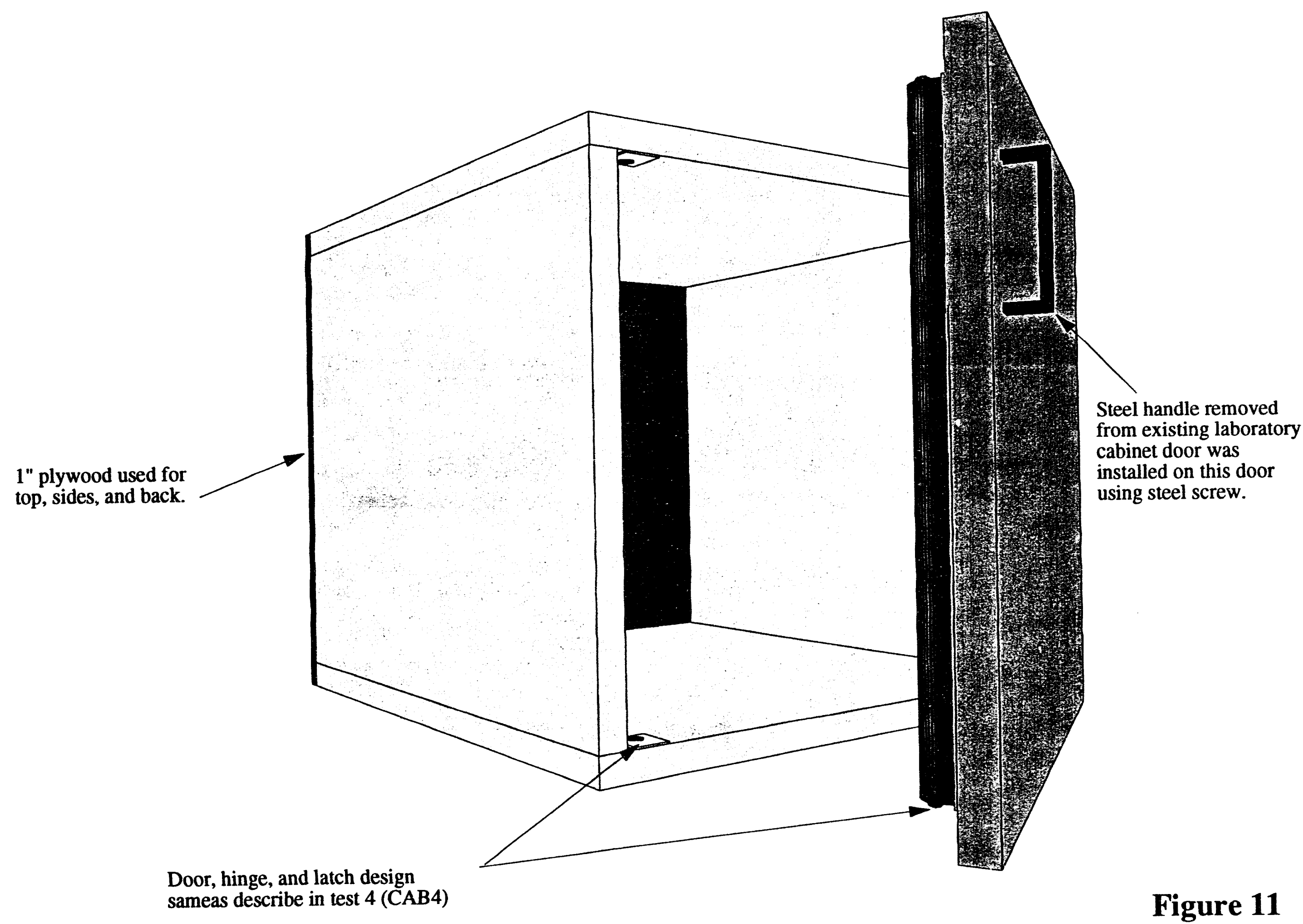


Temperature Data From Test FULLCAB1

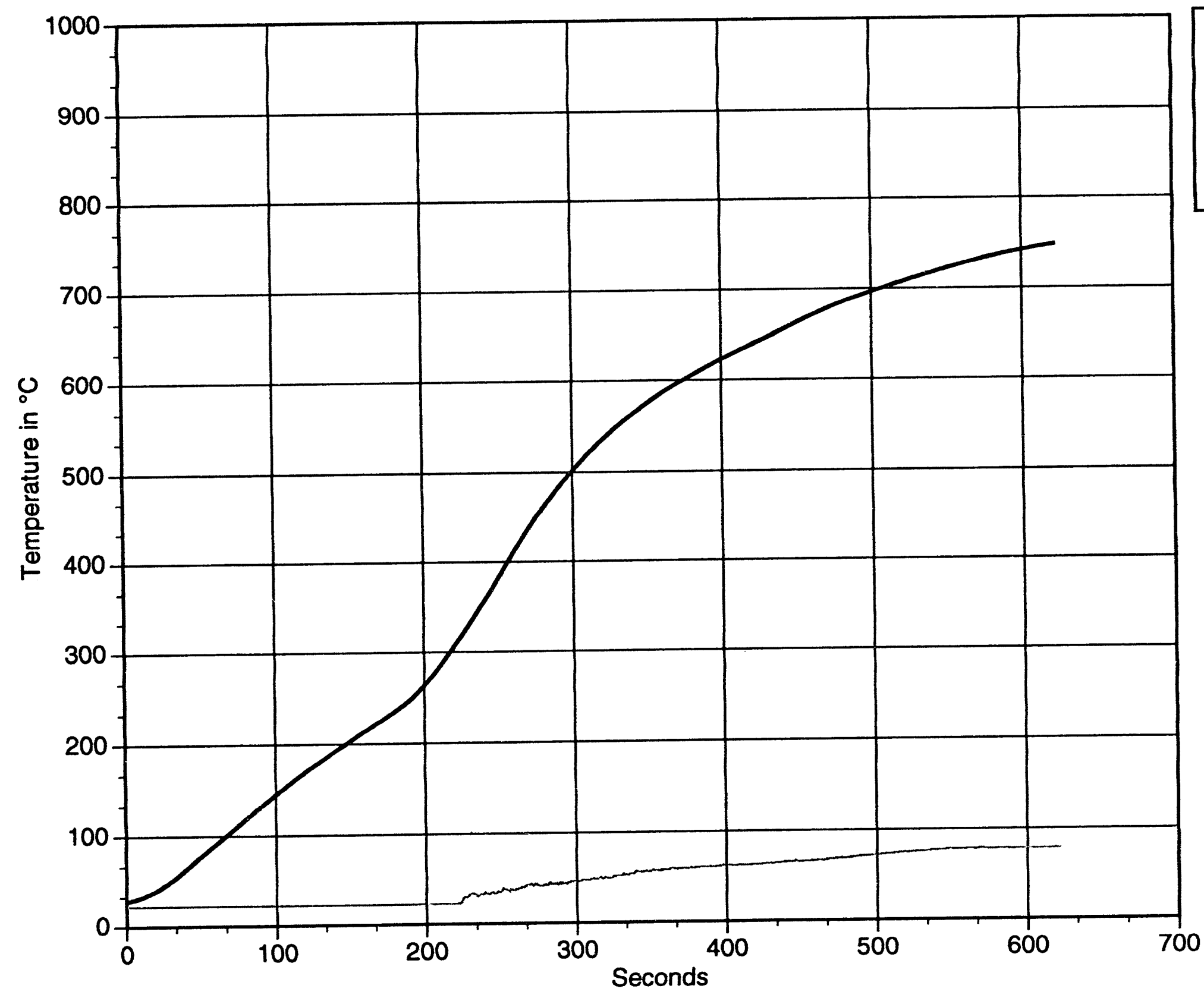

Inside Top of

Cabinet

Furnace

Temperature

Figure 12 
Temperature Data From Test FULLCAB2

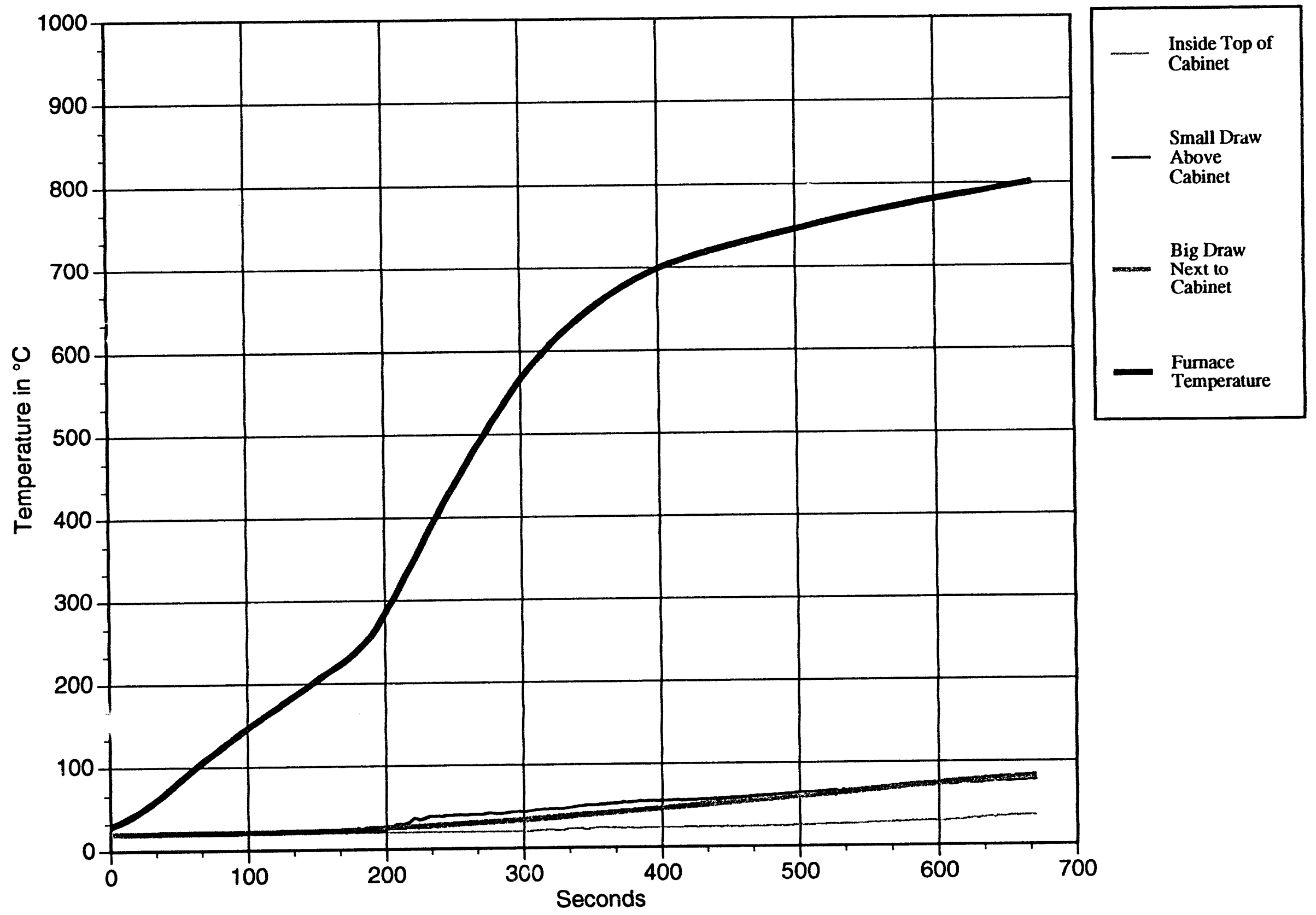

Figure 13 


$$
\begin{aligned}
& 0 \\
& 0 \\
& 0 \\
& 0 \\
& 0 \\
& 0 \\
& 0 \\
& 0 \\
& 0
\end{aligned}
$$




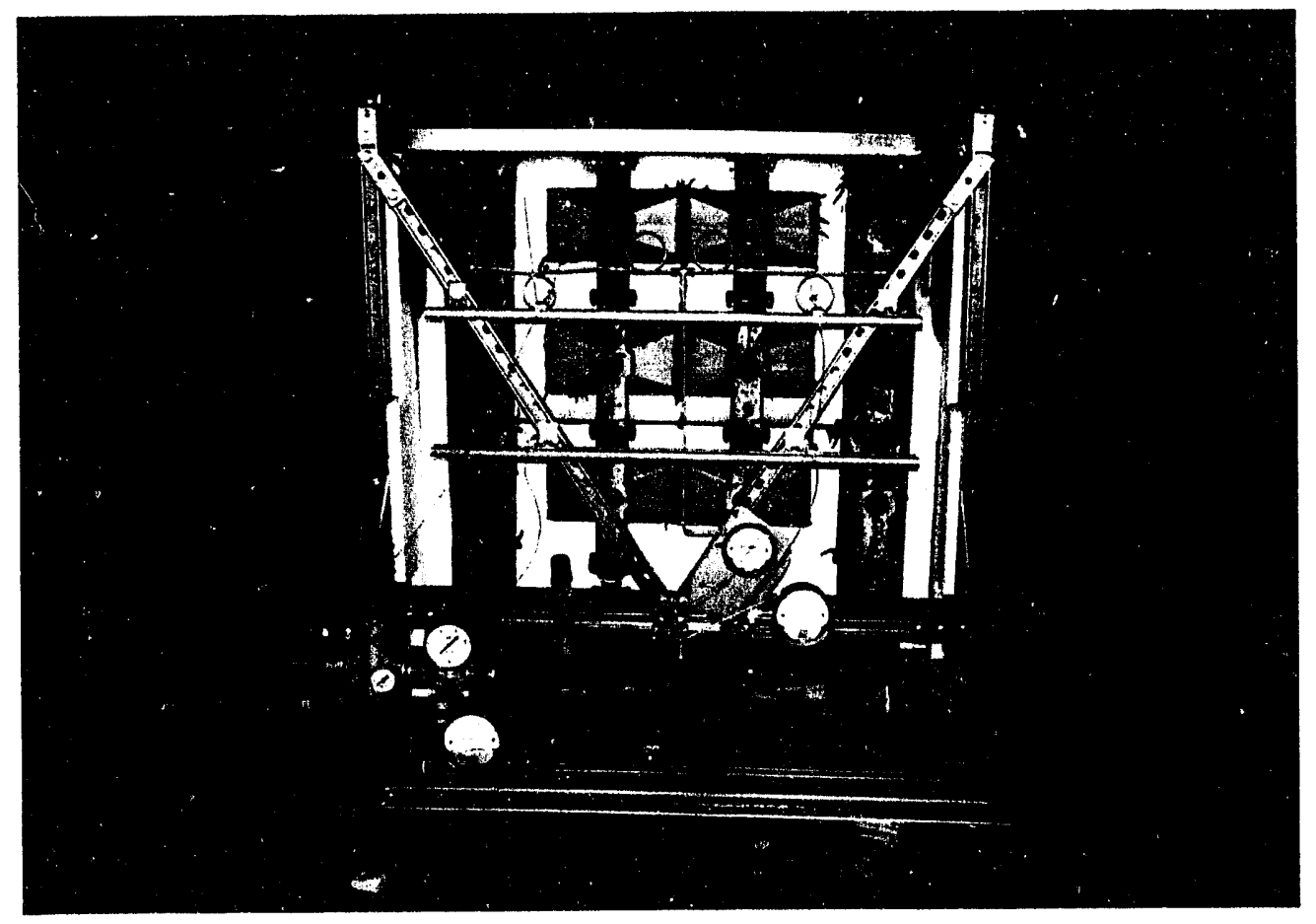

Photo 1: View of the Furnace showing manifolds, burners, control valves.

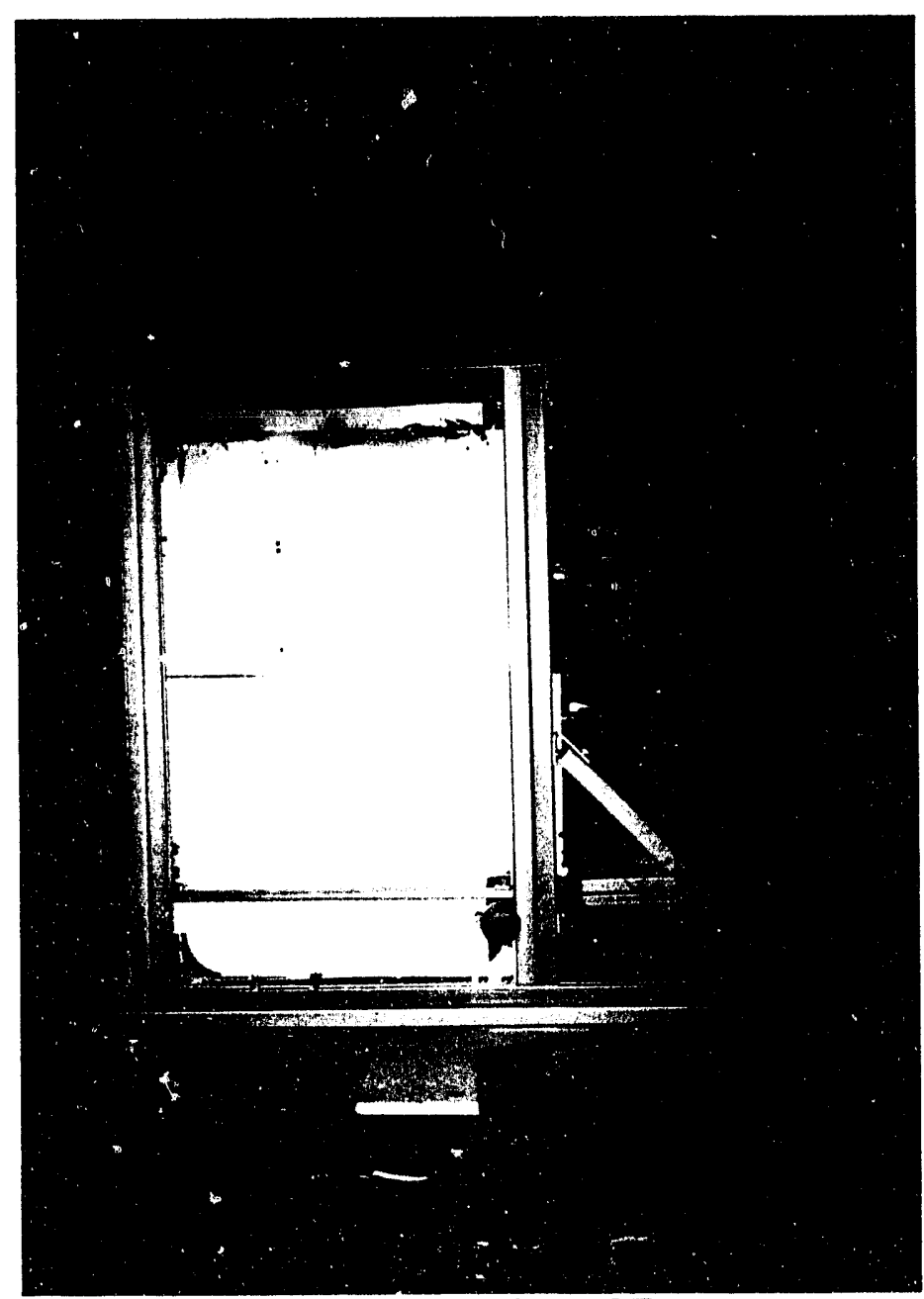

Photo 2: $\quad$ Side view of Furnace. 



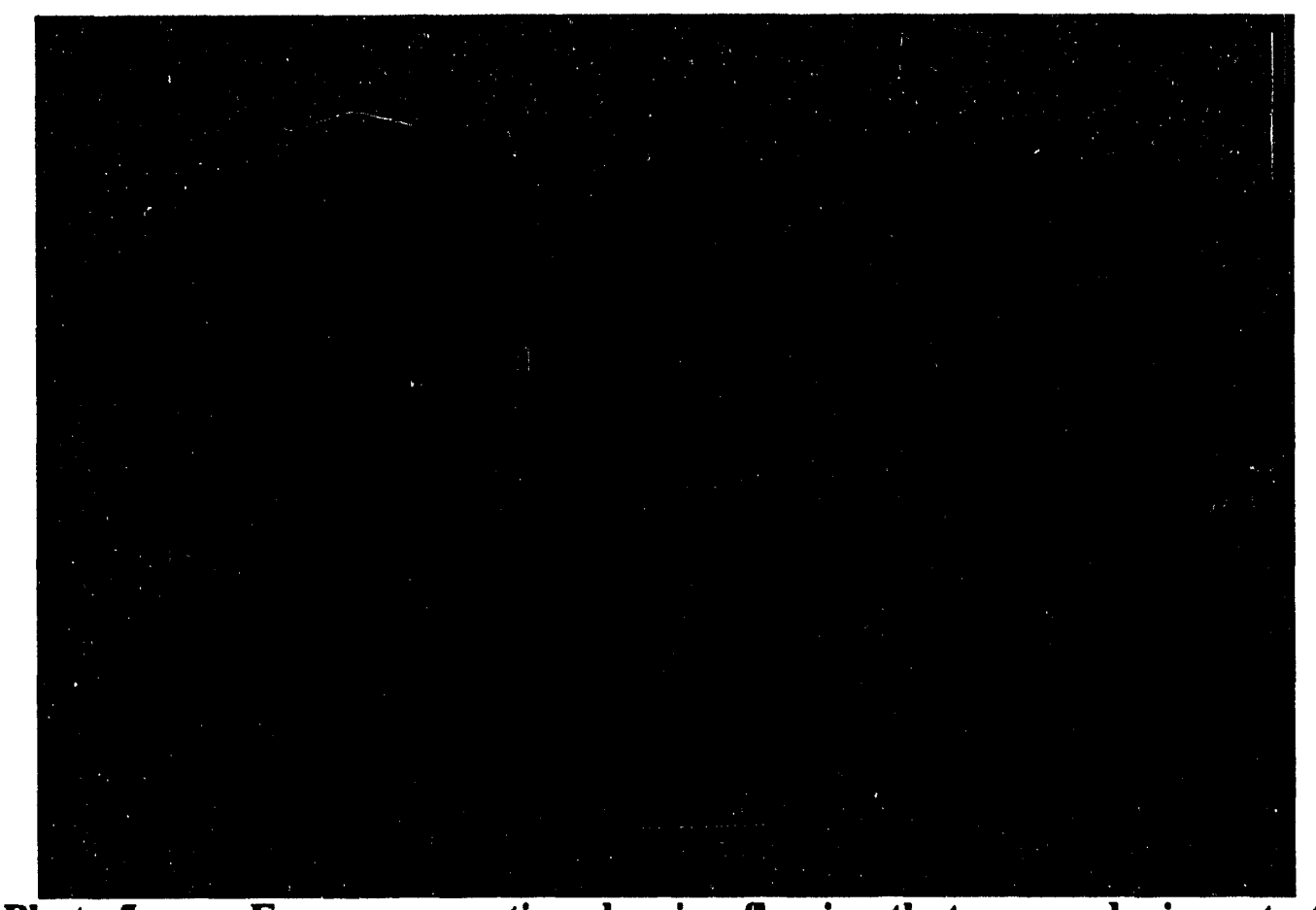

Photo 5: $\quad$ Furnace operation showing flaming that occurs during a test.

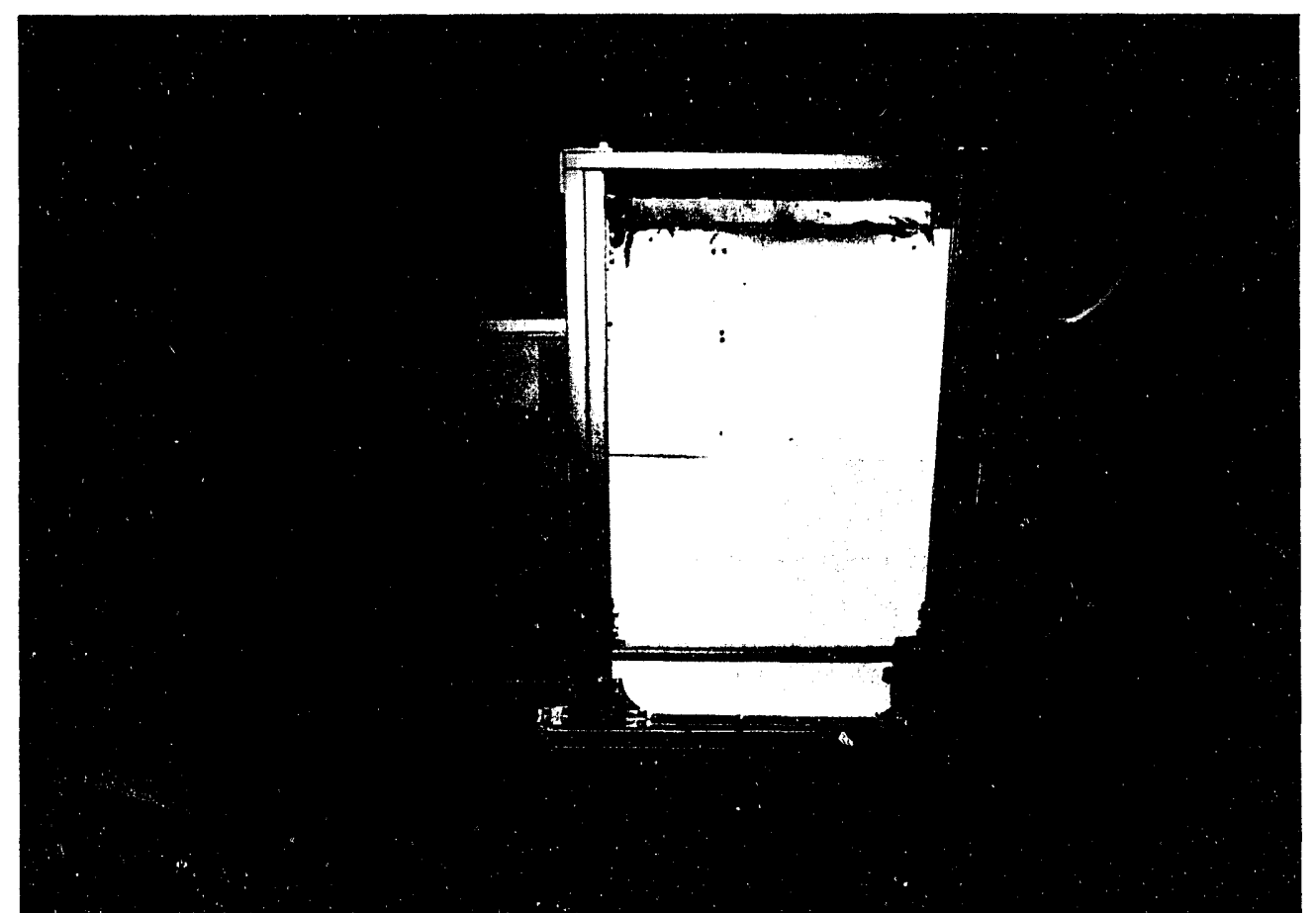

Photo 6: Set up for test 1 (CAB1) showing a side view of furnace and test cabinet . 


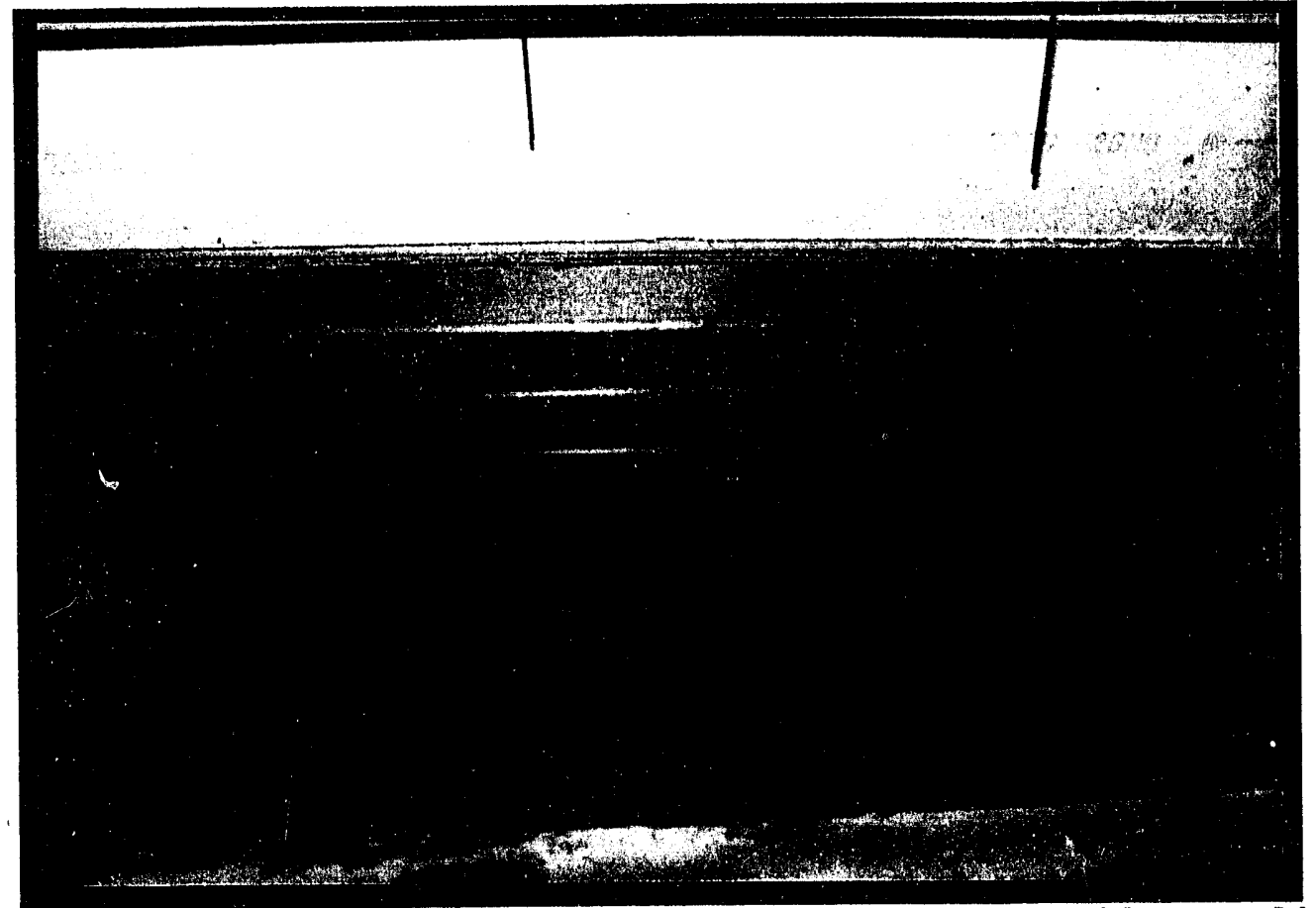

Photo 7: Set up for test 1 (CAB1) showing inside view of furnace with test cabinet in place.

Photo 8: $\quad$ Post test condition of cabinet, tested in test 1 (CAB1), showing heat patterns. 


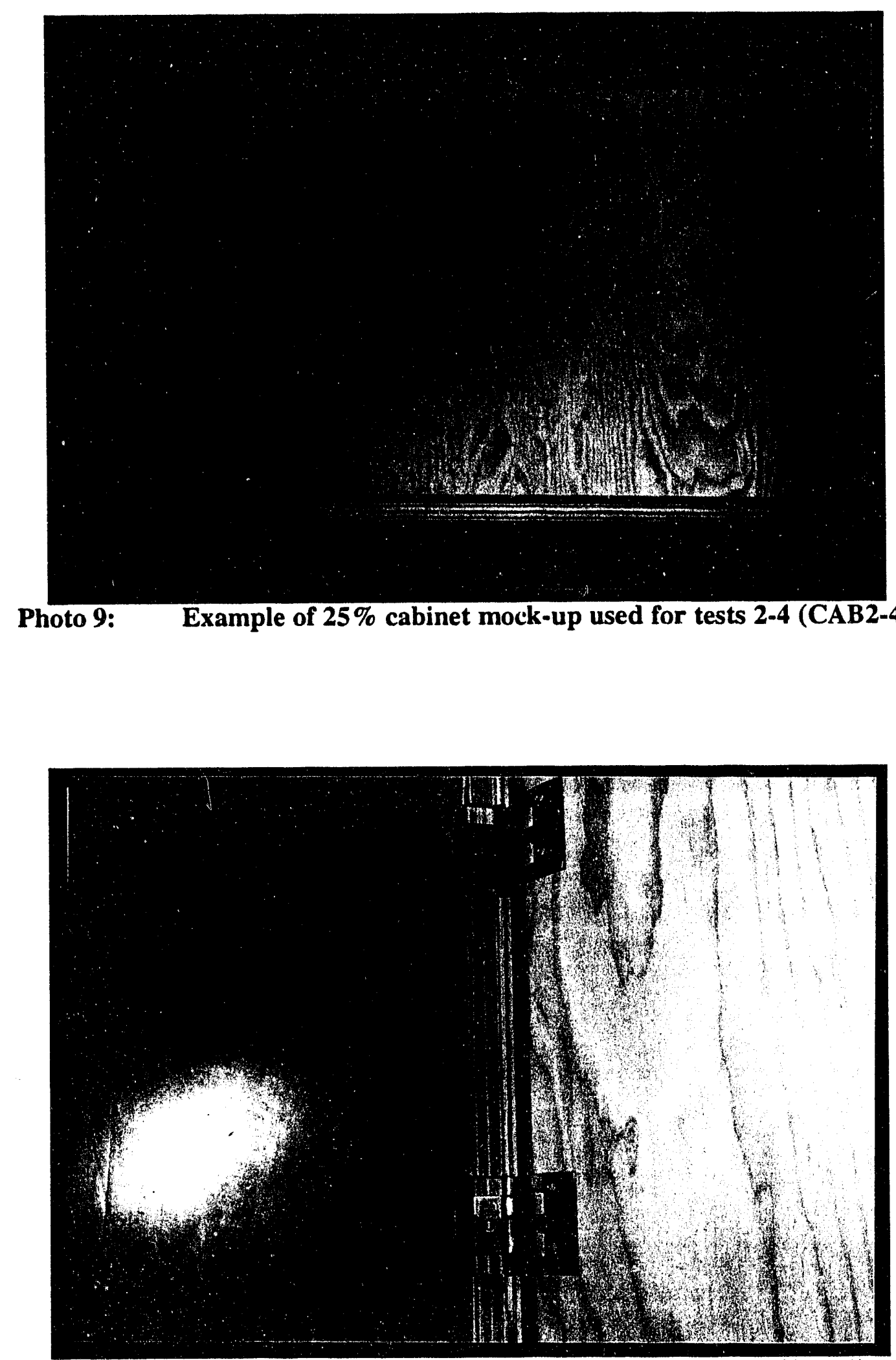

Photo 10: Hinges used in the cabinet mock-up for test 3 (CAB3). 


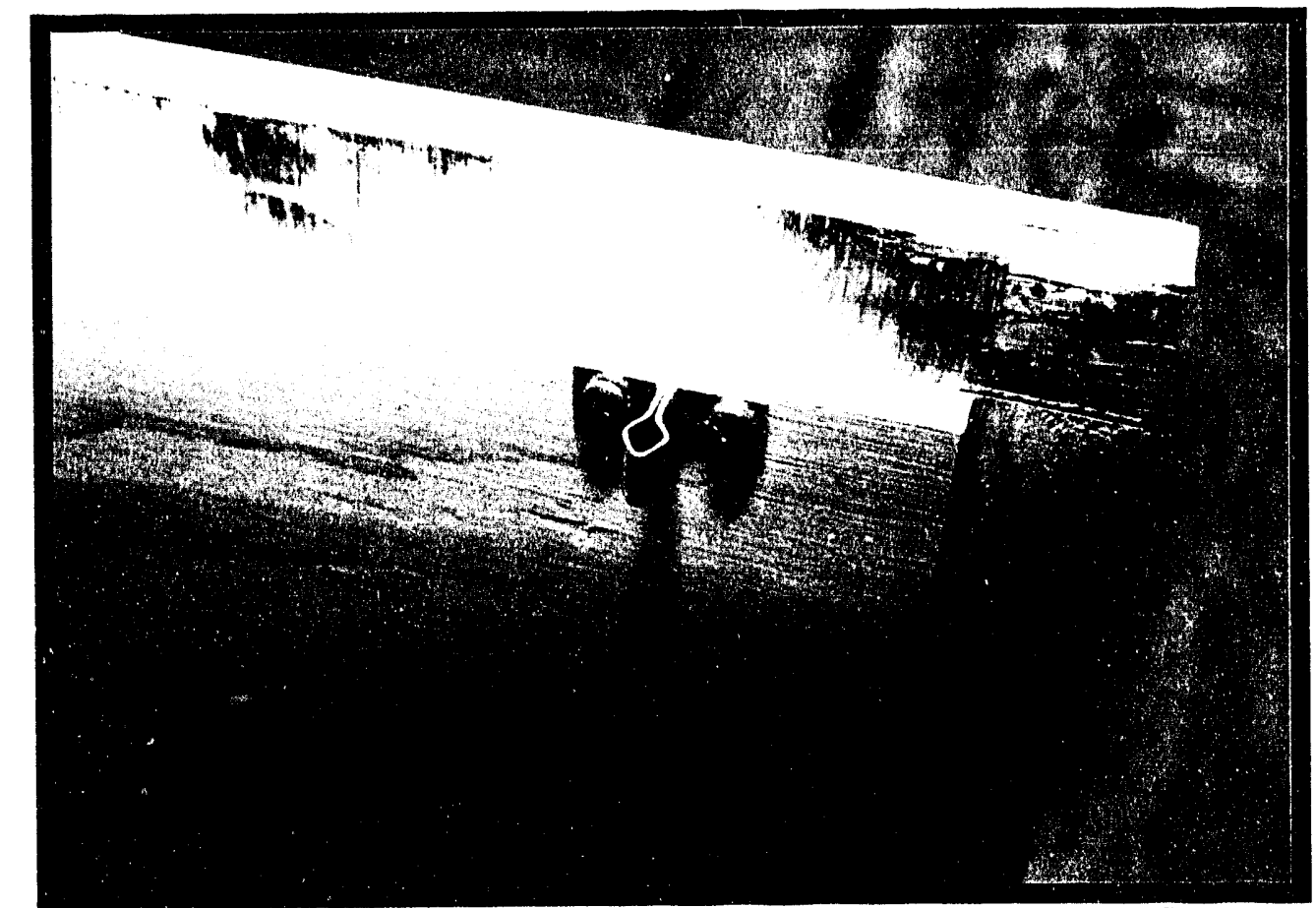

Photo 11: Latch mechanism mounted to the door of the cabinet tested in test 3 (CAB3).

Photo 12: Latch roller mechanism mounted to the wall of the cabinet tested in test 3 (CAB3). 

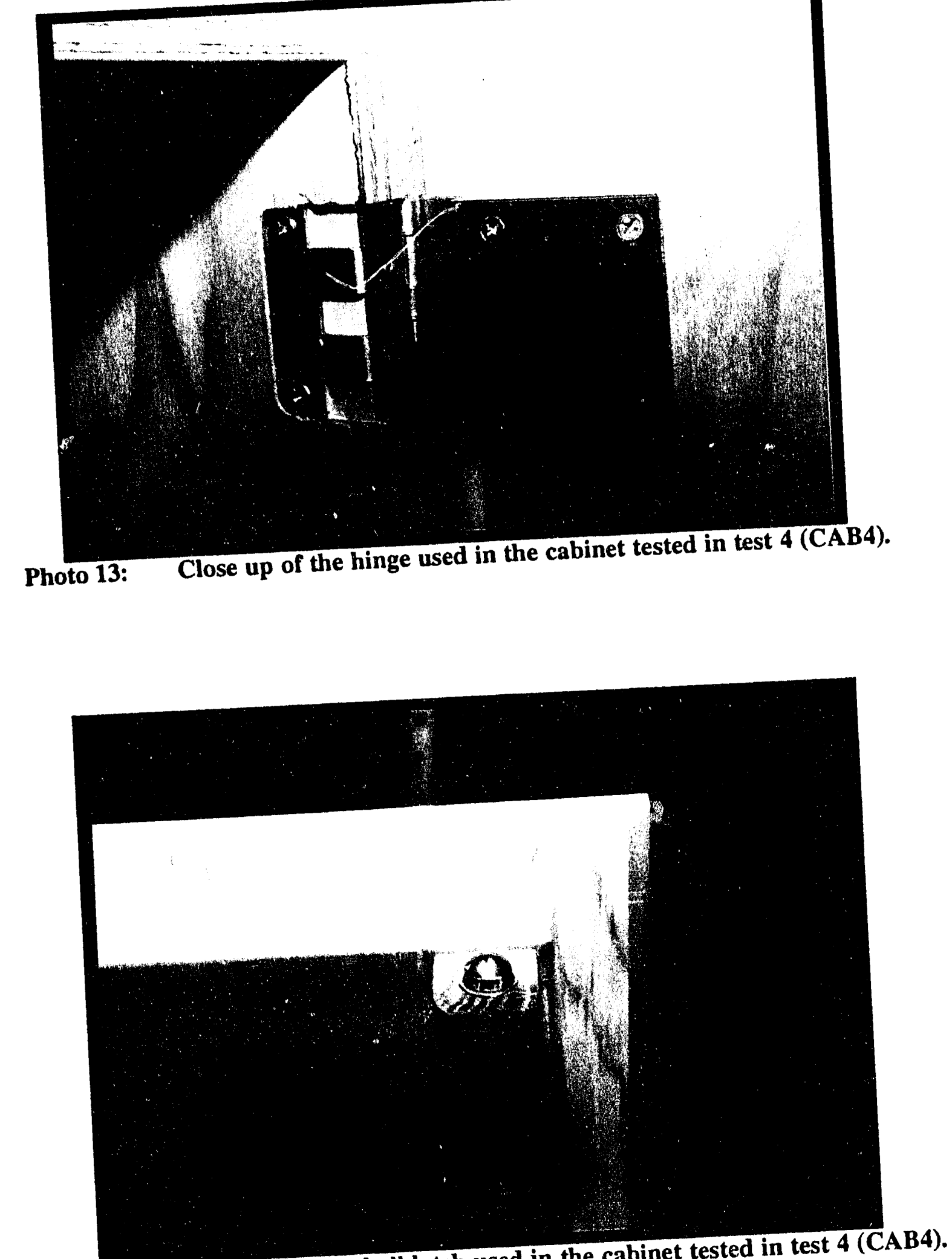

Close up of the ball latch used in the cabinet tested in test 4 (CAB4). 


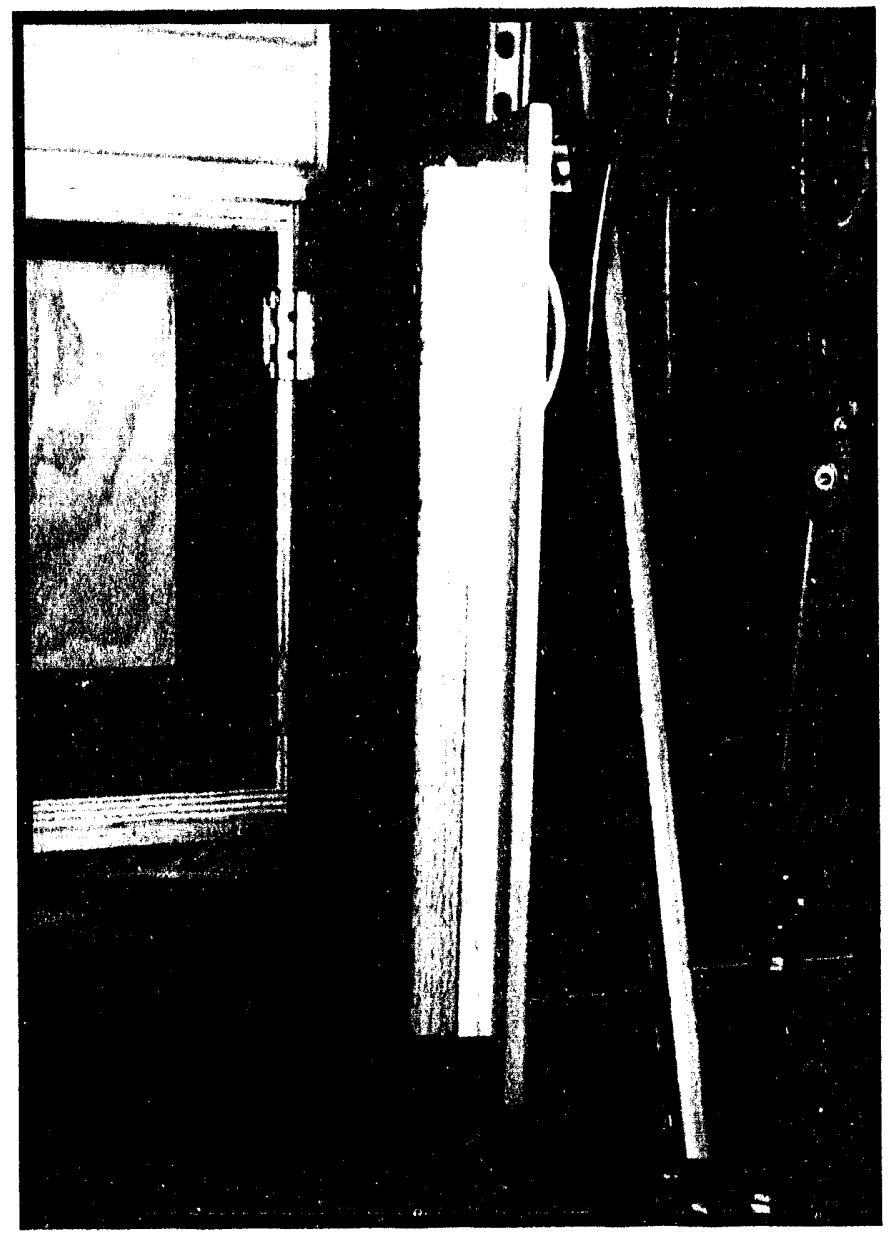

Photo 15: Door latch assembly used in the cabinets for tests 5 and 6 (FULLCAB 1 and 2).

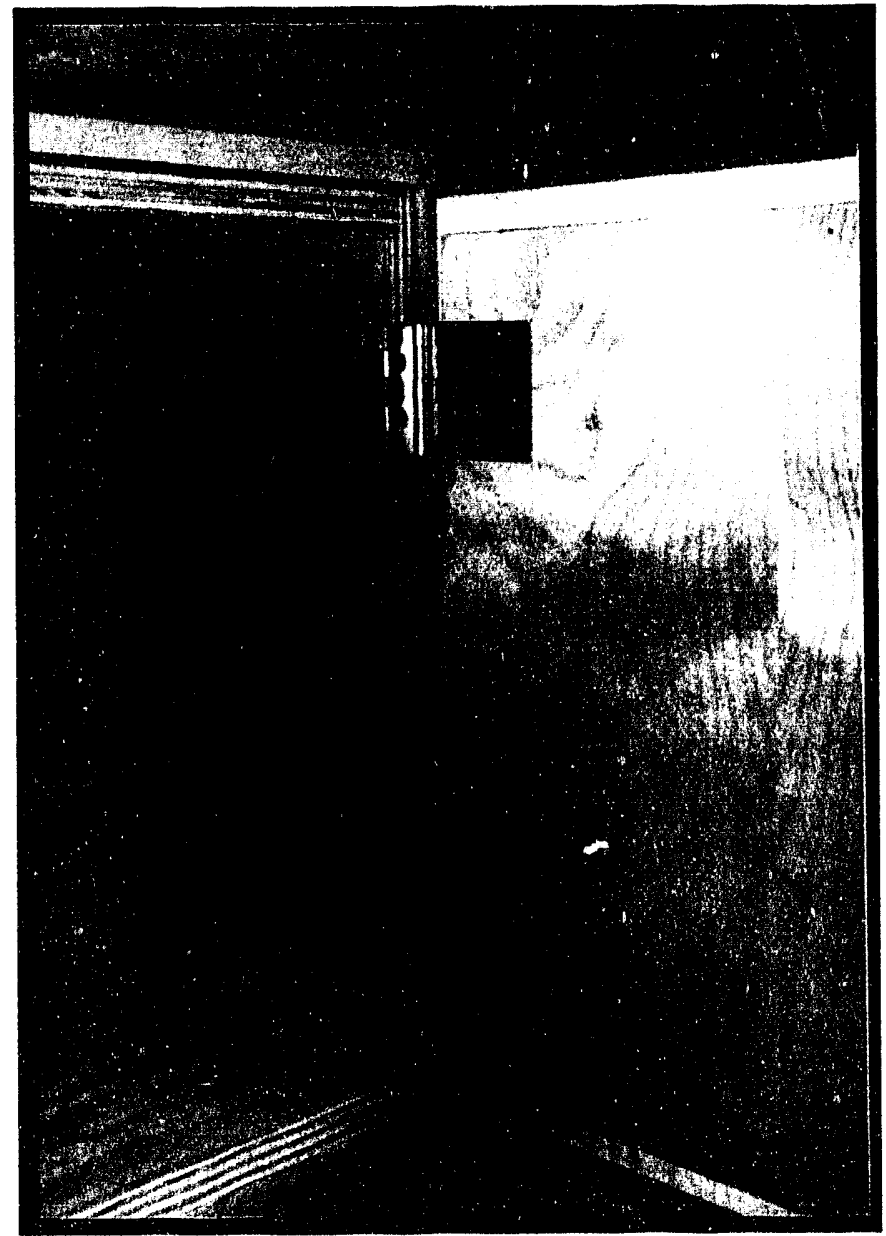

Photo 16: Large hinges used in the cabinets for tests 5 and 6 (FULLCAB 1 and 2). 


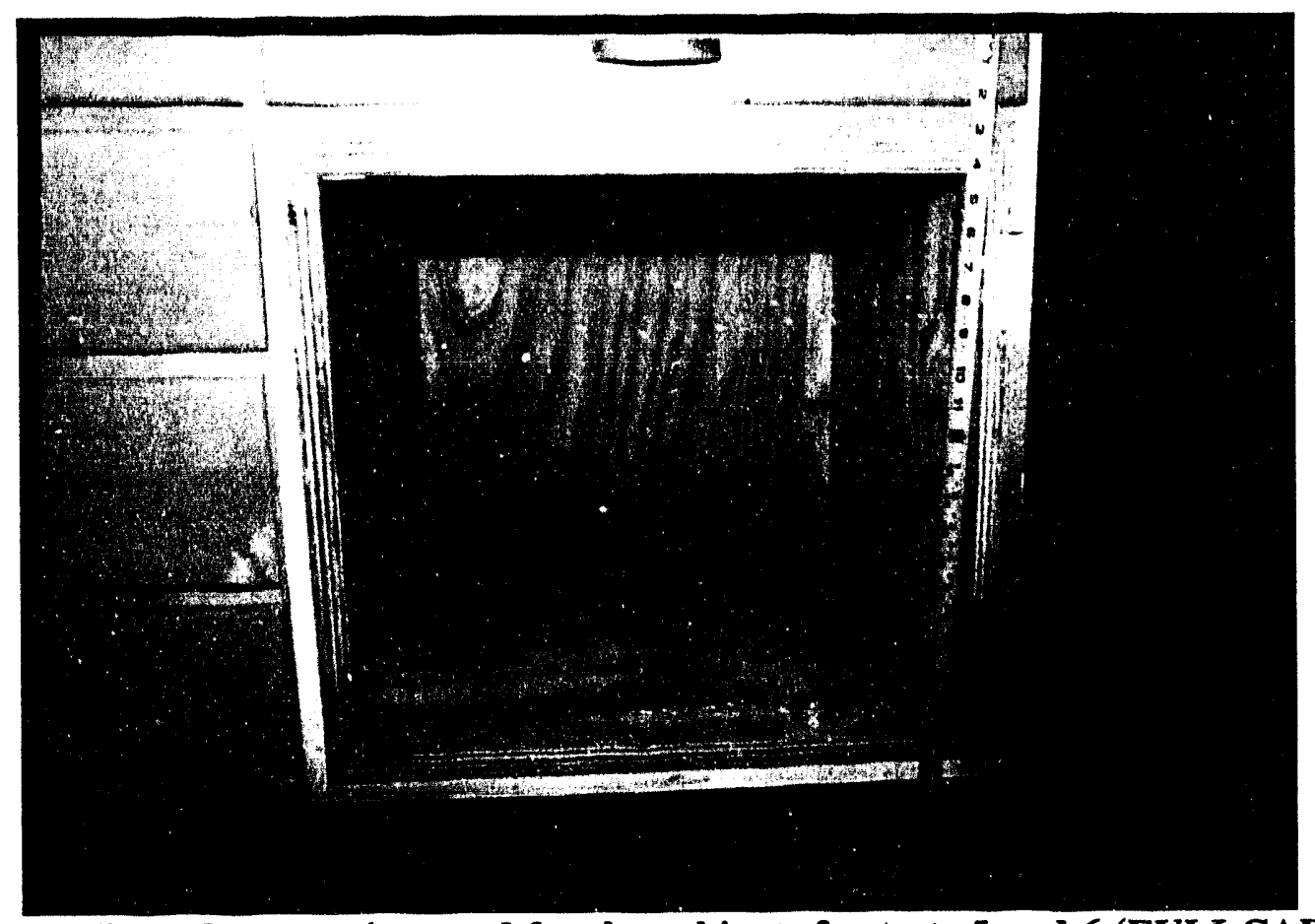

Photo 17: View of box section used for the cabinets for tests 5 and 6 (FULLCAB 1 and 2).

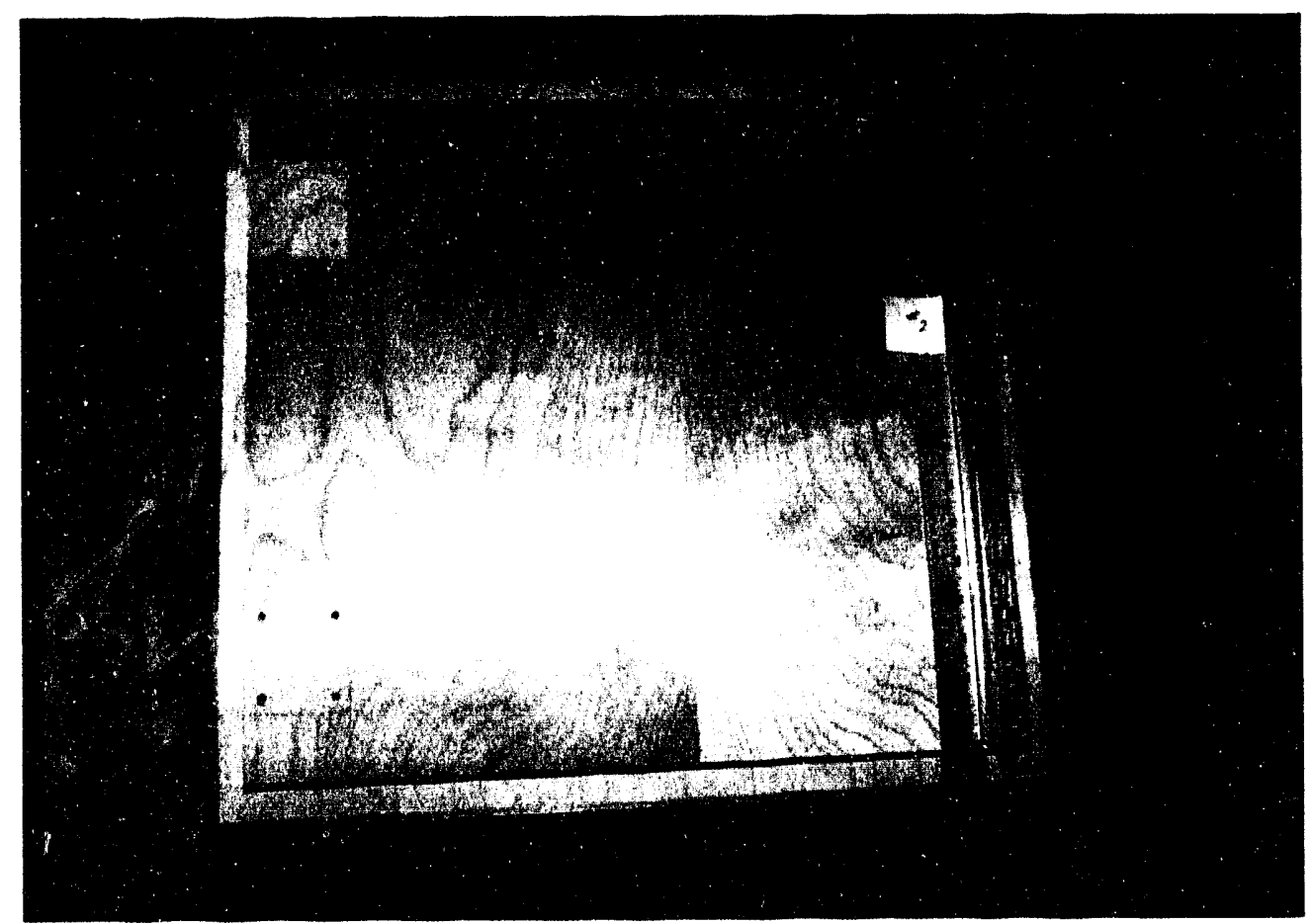

Photo 18: Back side of door used in the cabinets for tests 5 and 6 (FULLCAB 1 and 2). 


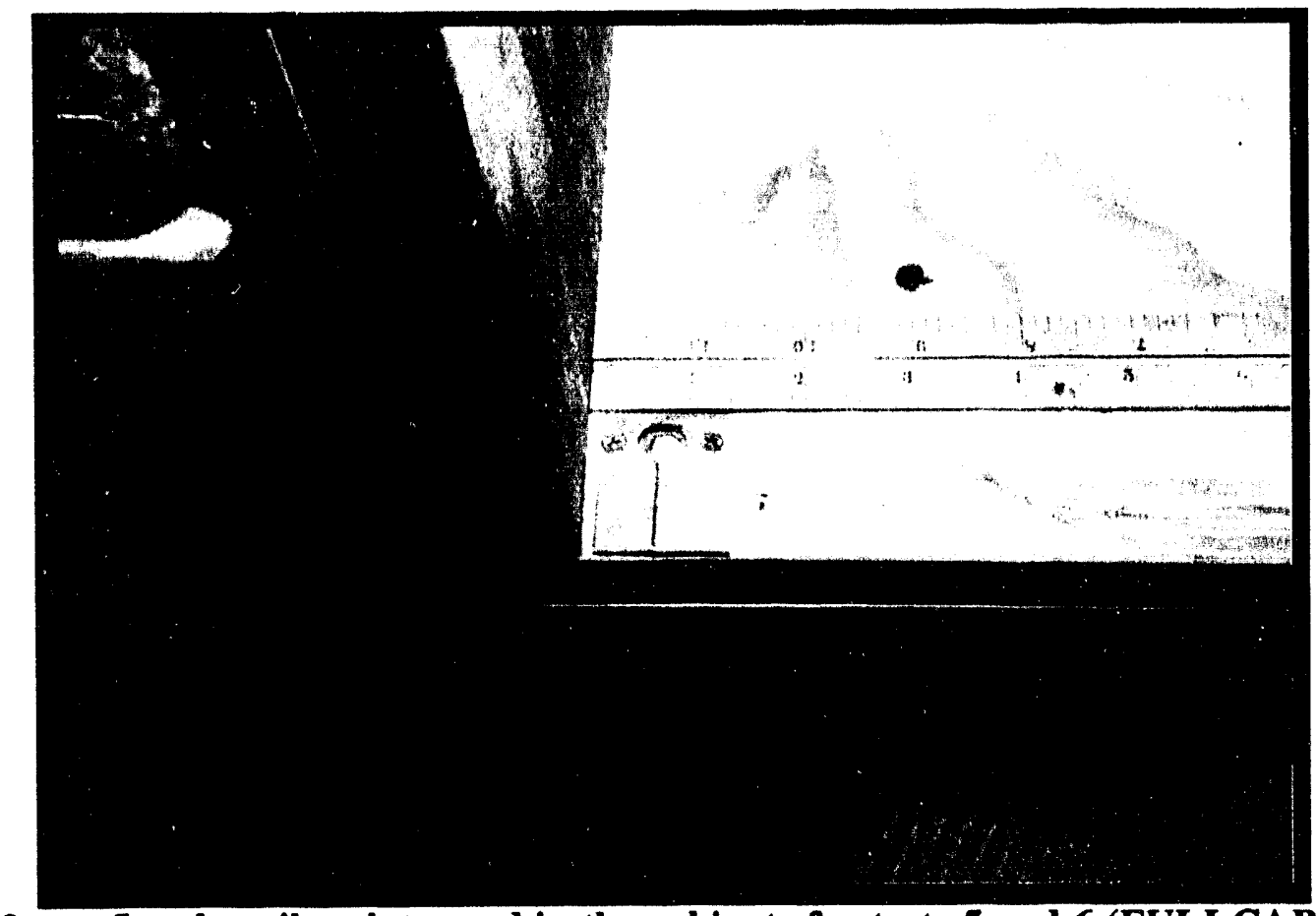

Photo 19: Latch strike plate used in the cabinets for tests 5 and 6 (FULLCAB 1 and 2).

Photo 20: Detail of trim piece used in the cabinets for tests 5 and 6 (FULLCAB 1 and 2). 

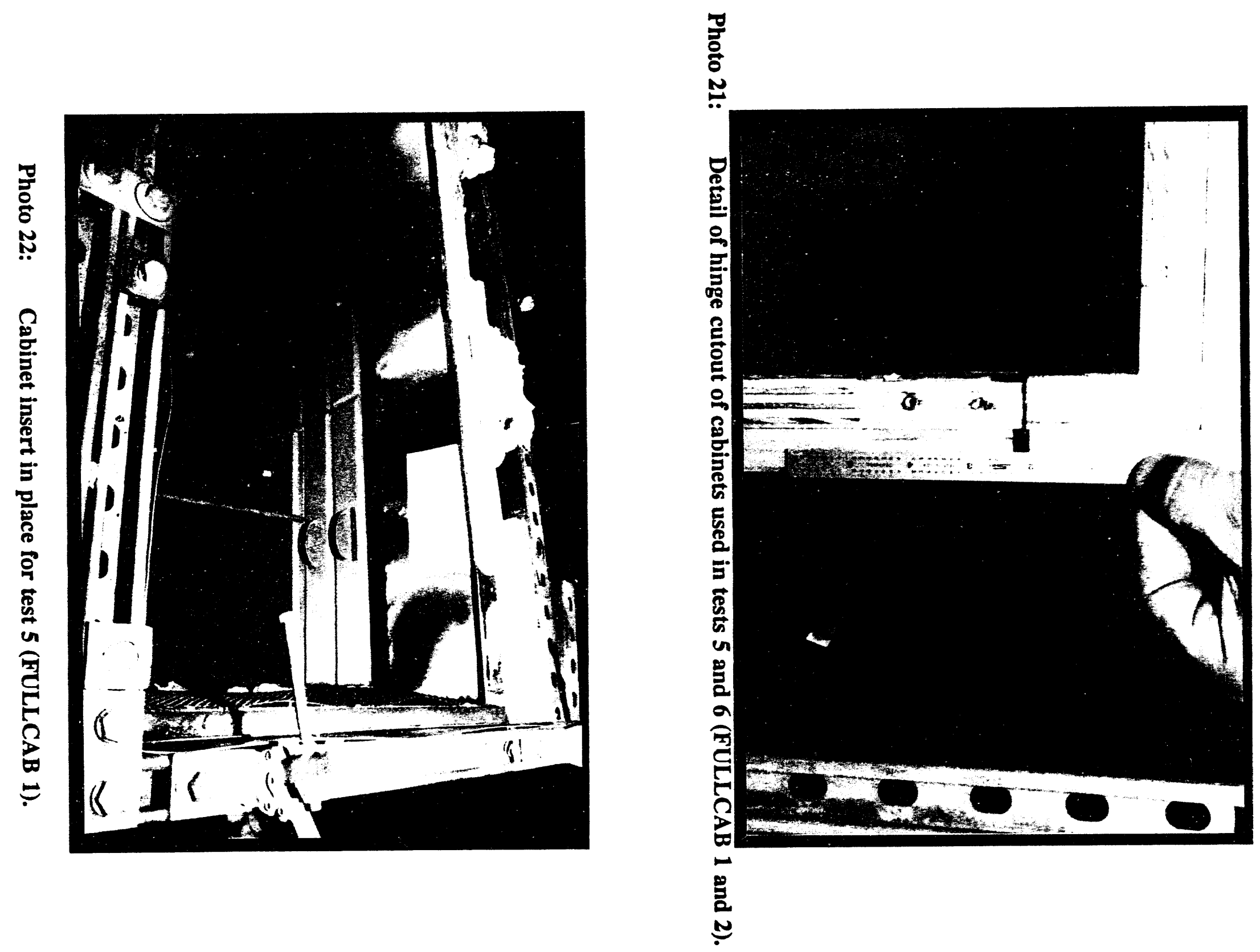



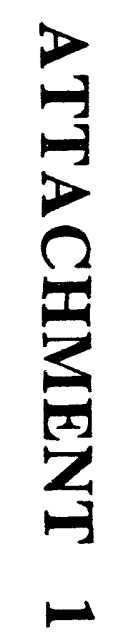




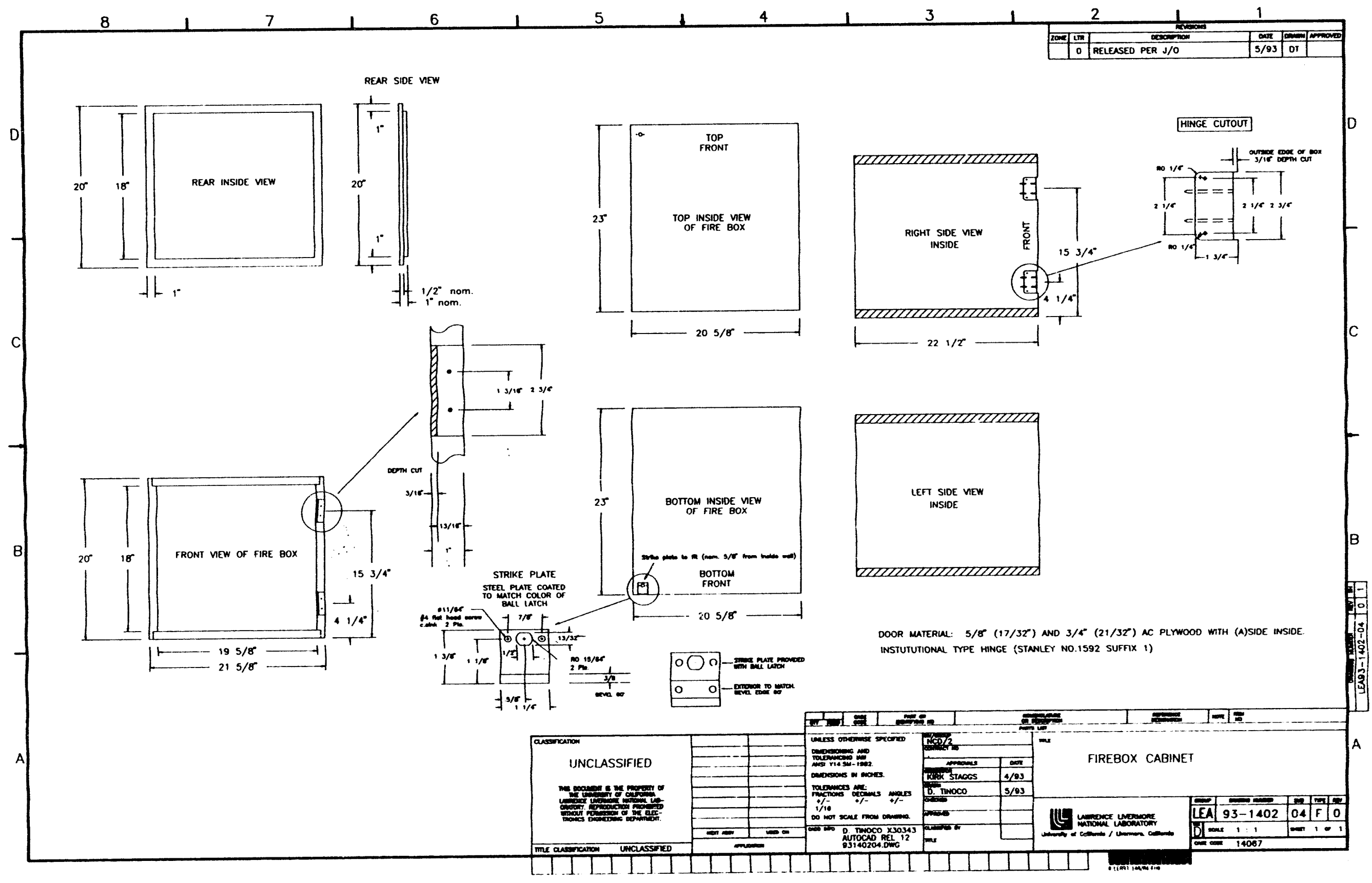

ming 


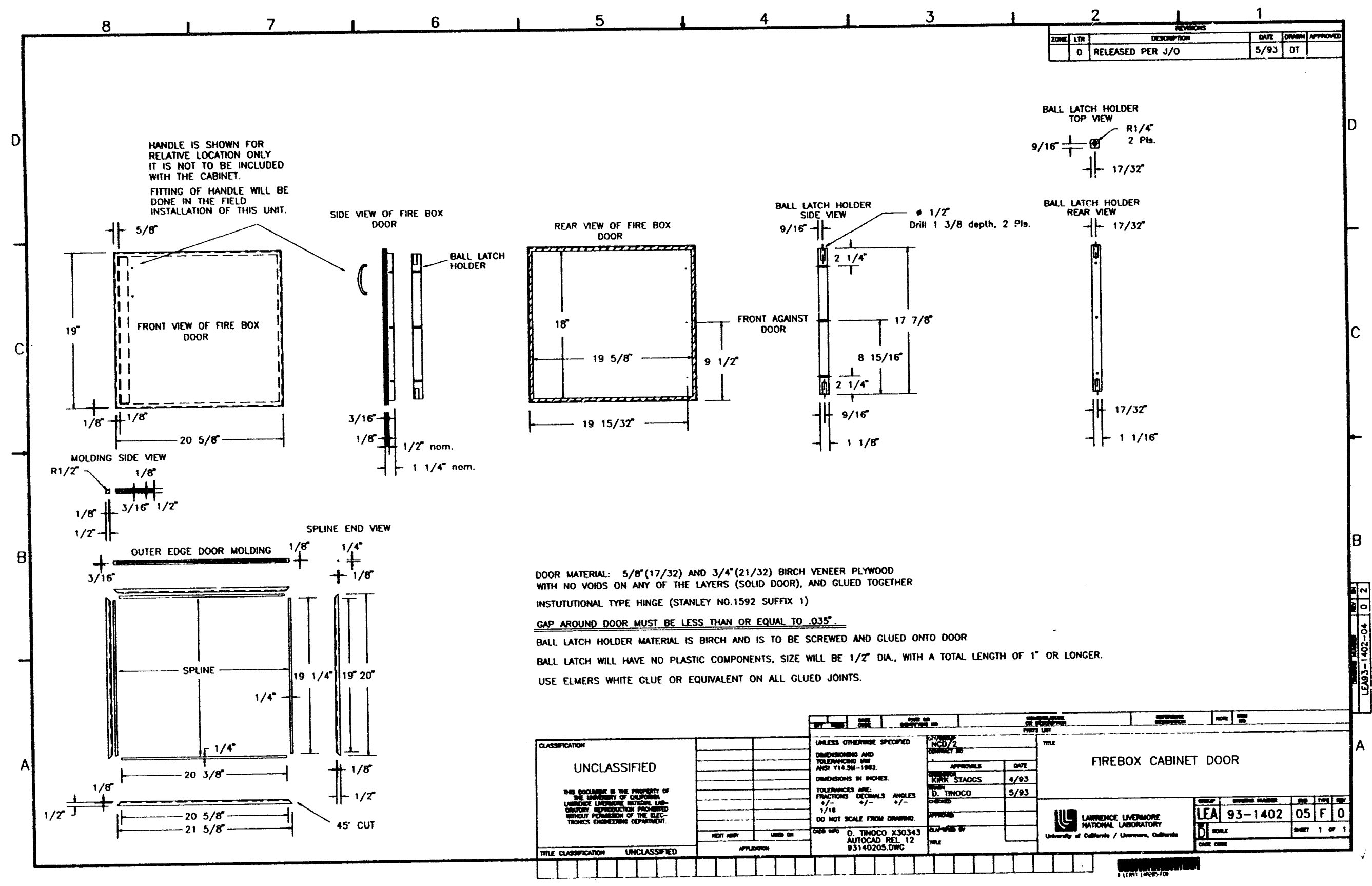

B. 

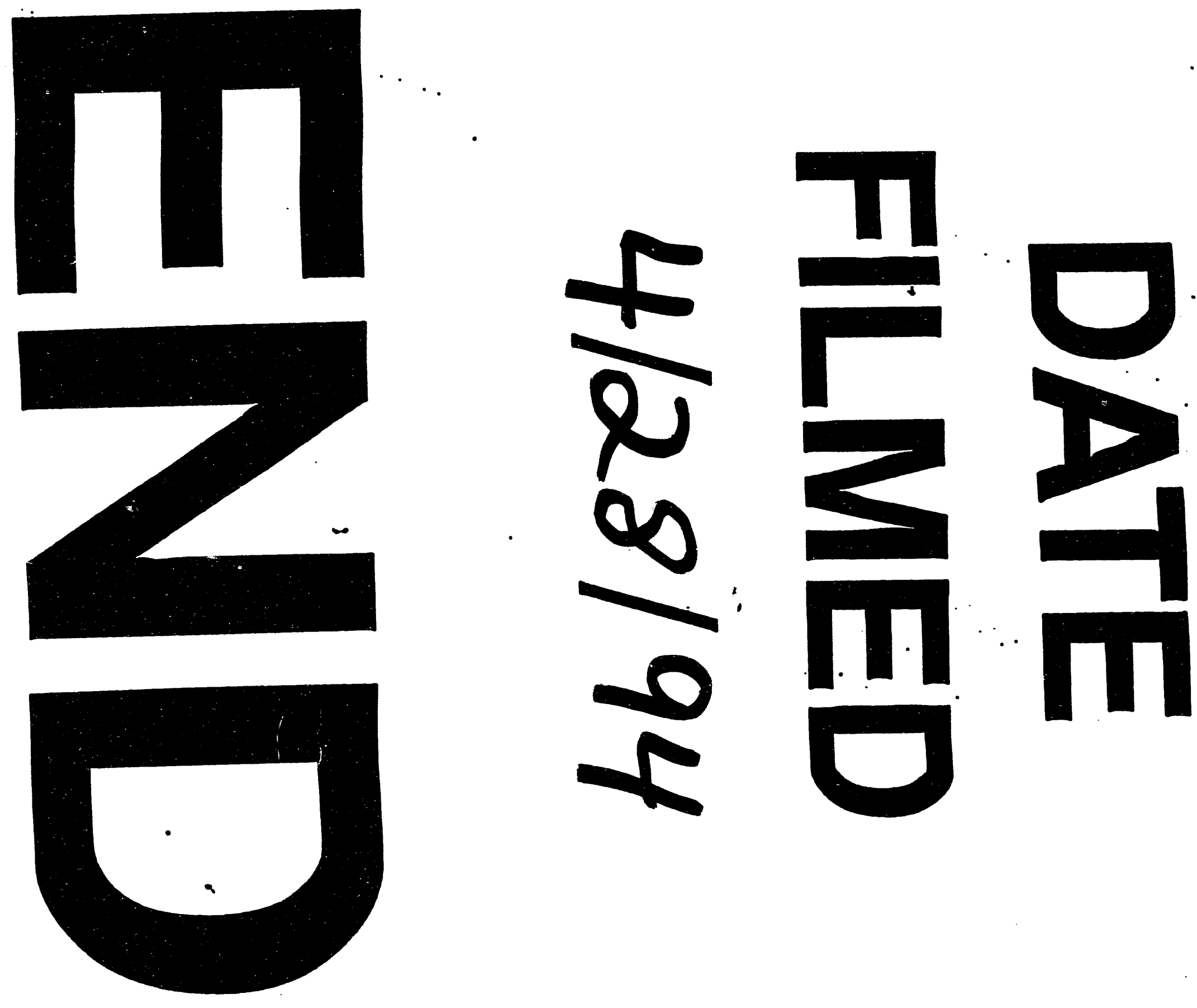
